\title{
Trafficking of Membrane Proteins to Cone But Not Rod Outer Segments Is Dependent on Heterotrimeric Kinesin-II
}

\author{
Prachee Avasthi, ${ }^{1,3}$ Carl B. Watt, ${ }^{1}$ David S. Williams, ${ }^{5}$ Yun Z. Le, ${ }^{6}$ Sha Li, ${ }^{1}$ Ching-Kang Chen, ${ }^{7}$ Robert E. Marc, ${ }^{1}$ \\ Jeanne M. Frederick, ${ }^{1}$ and Wolfgang Baehr ${ }^{1,2,4}$ \\ Departments of ${ }^{1}$ Ophthalmology and ${ }^{2}$ Neurobiology and Anatomy, and ${ }^{3}$ Graduate Program in Neuroscience, University of Utah Health Science Center, Salt \\ Lake City, Utah 84132, ${ }^{4}$ Department of Biology, University of Utah, Salt Lake City, Utah 84112, 5 Jules Stein Eye Institute, University of California, Los \\ Angeles, Los Angeles, California 90095-7065, ${ }^{\circ}$ Departments of Medicine and Cell Biology, University of Oklahoma Health Science Center, Oklahoma City, \\ Oklahoma 73104, and 7Department of Biochemistry and Molecular Biology, Virginia Commonwealth University, Richmond, Virginia 23298
}

Heterotrimeric kinesin-II is a molecular motor localized to the inner segment, connecting cilium and axoneme of mammalian photoreceptors. Our purpose was to identify the role of kinesin-II in anterograde intraflagellar transport by photoreceptor-specific deletions of kinesin family member 3A (KIF3A), its obligatory motor subunit. In cones lacking KIF3A, membrane proteins involved in phototransduction did not traffic to the outer segments resulting in complete absence of a photopic electroretinogram and progressive cone degeneration. Rod photoreceptors lacking KIF3A degenerated rapidly between 2 and 4 weeks postnatally, but the phototransduction components including rhodopsin trafficked to the outer segments during the course of degeneration. Furthermore, KIF3A deletion did not affect synaptic anterograde trafficking. The results indicate that trafficking of membrane proteins to the outer segment is dependent on kinesin-II in cone, but not rod photoreceptors, even though rods and cones share similar structures, and closely related phototransduction polypeptides.

\section{Introduction}

Rod and cone photoreceptors have evolved into highly polarized structures consisting of three distinct areas: the outer segment containing membrane discs housing proteins involved in phototransduction, the inner segment in which biosynthesis occurs, and the synaptic terminal that transmits excitation by light to downstream neurons. The inner segment (cell body) connects to an outer segment through a narrow $9+0$ cilium and to the synaptic terminal by a slender axon (for review, see http://webvision.med.utah.edu/). Outer segments of rods and cones are renewed approximately every 10 d (Young, 1967; LaVail, 1976; Besharse and Hollyfield, 1979) by disc membrane assembly at the proximal end, with concomitant disc shedding at the distal end, and phagocytosis of shed disc membrane by the adjacent retinal pigment epithelium (RPE) (Young and Bok, 1969; Anderson et al., 1978; Strauss, 2005). Daily renewal of $\sim 10 \%$ ( $\sim 100$ discs $)$ of the outer segment membrane requires a high rate of biosynthesis to replace outer segment (OS) proteins, with reliable transport and targeting pathways.

A central question concerns the transport of membrane proteins, particularly the mechanisms of targeting to the outer seg-

Received Aug. 13, 2009; accepted Sept. 14, 2009.

This work was supported by National Institutes of Health Grants EY08123, EY019298 (W.B.), EY07042, EY13408 (D.S.W.), EY013811 (C.-K.C.), EY014800-039003 (National Eye Institute core grant), American Health Assistance Foundation Grant M2008-059 (Y.Z.L.), Foundation Fighting Blindness (FFB) Grant BR-CMM-0808-0453-UOK (Y.Z.L.), by a center grant of the FFB to the University of Utah, and unrestricted grants to the Departments of Ophthalmology of the University of Utah from Research to Prevent Blindness (New York). We thank Li Jiang for assisting in photopic ERG analyses and Zackery Oakey for technical assistance.

Correspondence should be addressed to Wolfgang Baehr, John A. Moran Eye Center, University of Utah Health Science Center, Salt Lake City, UT 84132. E-mail: wbaehr@hsc.utah.edu.

DOI:10.1523/JNEUROSCI.3976-09.2009

Copyright $\odot 2009$ Society for Neuroscience $\quad 0270-6474 / 09 / 2914287-12 \$ 15.00 / 0$ ments and intraflagellar transport (IFT) through the cilium. Rhodopsin, the visual pigment of rods, is synthesized by endoplasmic reticulum (ER)-associated ribosomes and exported to the Golgi apparatus (for review, see Sung and Tai, 2000). Rhodopsin-laden vesicles emerge from the trans-Golgi network (TGN) to traffic along microtubules toward the minus end near the microtubule-organizing center and to the base of the cilium in which they fuse with the plasma membrane (Deretic, 1998; Williams, 2002). Finally, cargo is assembled for IFT through the cilium (Rosenbaum and Witman, 2002). IFT is thought to be powered by heterotrimeric kinesin-II, a microtubule-based and plus end-oriented molecular motor (Cole et al., 1992; Scholey, 2008) associated with IFT particles (Pazour et al., 2002; Baker et al., 2003).

The kinesin superfamily consists of at least 15 members (kinesin-1 to kinesin-13, and kinesin-14a and kinesin-14b). The kinesin-2 subfamily consists of two anterograde motors: a homodimeric and a heterotrimeric kinesin. The homodimeric kinesin-2 [kinesin family member 17 (KIF17) subunits] is an ortholog of OSM-3 found in Caenorhabditis elegans (Snow et al., 2004). The heterotrimeric motor, kinesin-II, consists of KIF3A, KIF3B, and KAP3 (kinesin-associated protein 3) subunits (Yamazaki et al., 1995, 1996). Kinesin-II motor subunits and homologues contain an N-terminal motor domain and globular tail domain separated by an $\alpha$-helical coiled coil. Known functions of kinesin-II are diverse and include melanosome dispersion in melanophores, and ER-to-Golgi transport in frog cell lines (Le Bot et al., 1998; Tuma et al., 1998); transport of flagellar component protein complexes in Chlamydomonas rheinhardtii (Cole et al., 1998); and ciliogenesis in Tetrahymena, C. elegans, 
and sea urchin embryos (Tabish et al., 1995; Morris and Scholey, 1997; Brown et al., 1999), as well as mammalian renal ciliogenesis (Lin et al., 2003).

KIF3A has been found in the inner segment, at the connecting cilium and axoneme (Whitehead et al., 1999), and at the photoreceptor ribbon synapse (Muresan et al., 1999; tom Dieck et al., 2005). Global mouse Kif3a knock-outs are lethal and lack cilia on all cells of the embryonic node, which prevents leftward flow of morphogen and results in left-right asymmetry defects (Marszalek et al., 1999). Inactivation of KIF3A in renal epithelial cells prevented formation of primary cilia and caused mislocalization of EGF receptor, mimicking the phenotype observed in polycystic kidney disease (Lin et al., 2003). Rod-specific Kif3a knock-out with mouse lines expressing Cre recombinase in rod photoreceptors caused rapid photoreceptor degeneration and abnormal accumulations of opsin in the rod inner segment (Marszalek et al., 2000; Jimeno et al., 2006), suggesting a role for kinesin-II in membrane protein transport. In this communication, we explored the effects of cone-specific deletion of KIF3A using a Kif $3 a^{\text {flox } / f l o x}$ mouse line (Marszalek et al., 2000) and a transgenic mouse expressing Cre recombinase in cones (Le et al., 2004). We also generated KIF3A rod deletions using a mouse line uniformly expressing Cre recombinase in rods ( $\mathrm{Li}$ et al., 2008) to test for trafficking of membrane proteins to rod outer segments (ROSs). We show that transport of cone outer segment (COS) membrane proteins in $\mathrm{Kif3}^{-l-}$ cones is severely impeded, resulting in absence of the entire cone phototransduction cascade in the mutant outer segments. Surprisingly, the rod outer segment membrane proteins, including rhodopsin, traffic in KIF3A-deficient rods during the entire course of degeneration, thereby ruling out their dependence on heterotrimeric kinesin-II. These results reveal distinct mechanisms for rod and cone anterograde IFT and imply that, during evolution, membrane protein transport pathways diverged despite similar photoreceptor morphologies.

\section{Materials and Methods}

Generating photoreceptor Kif3a conditional knock-outs. The Kif3 flox/flox mice were from the same colony used in previous studies (Marszalek et al., 1999). The Hrgp-Cre (Le et al., 2004) mice showed normal cone function throughout the investigated life and no expression in rods, as shown by $\beta$-gal expression in R26R mice. The Rho-Cre mice (iCre-75) (Li et al., 2008) are also stable up to 8 months of age. For cone-specific knock-out, Hrgp-Cre mice were mated with Kif $3 a^{\text {flox } / f l o x}$ mice and the resulting heterozygous ${ }^{c} \mathrm{Kif} 3 a^{-/ W T}$ mice were genotyped using primers CreChk2.F (5' -AATGCTTCTGTCCGTTTGCCG) and CreChk2.R (5'CCATTGCCCCTGTTTCACTATCC) generating an 878 bp amplicon indicating presence of the Cre transgene. For rod-specific knockout, Hrgp-Cre mice were replaced by iCre75 mice. iCre75 mice were genotyped by PCR with RH1.1 primer ( 5 ' -TCAGTGCCTGGAGTTGCGCTGTGG) and iCre550 primer (5'-CTTAAAGGCCAGGGCCTGCTTGGC). Kif $3 a$ genotyping was done as described previously (Marszalek et al., 1999) using primers P1 (5'-AGGGCAGACGGAAGGGTGG), P2 (5'-TCTGTGAGTTTGTGACCAGCC), and P3 (5'-GGTGGGAGCTGCAAGAGGG).

Antibodies. Antibody sources were described previously (Baehr et al., 2007; Zhang et al., 2007). The anti-rhodopsin antibody (VPP) was raised in rabbits against the N-terminal peptide 16-CTGVVRSPFEQP-27 of mouse opsin. Additional antibodies were provided by the following investigators: Stefan Heller (Stanford University, Palo Alto, CA), antiR9AP antibody; Françoise Haeseleer (University of Washington, Seattle WA), anti-UNC119; Wieland Huttner (Max Planck Institute of Molecular Cell Biology and Genetics, Dresden, Germany), antiProm1; Andrew F. X. Goldberg (Oakland University, Rochester, MI), anti-peripherin/rds. Commercial antibodies were as follows: anti-Cre antibody (Covance), anti-CNGA3 (Santa Cruz Biotechnology), and anti- glyceraldehyde-3-phosphate dehydrogenase (GAPDH) and anti-KIF3A monoclonal antibodies (Sigma-Aldrich).

Confocal immunolocalization. Eyes from mice aged $13 \mathrm{~d}$ through 4 months were harvested under ambient laboratory illumination and immersion-fixed using freshly prepared $4 \%$ paraformaldehyde in $0.1 \mathrm{M}$ phosphate buffer, $\mathrm{pH} 7.4$, for $2 \mathrm{~h}$ on ice. Eyecups were then moved to $15 \%$ sucrose in phosphate buffer for $1 \mathrm{~h}$ and then to $30 \%$ sucrose overnight for cryoprotection. Sections ( $12 \mu \mathrm{m}$ thick) were blocked using $10 \%$ normal donkey serum in $0.1 \mathrm{M}$ phosphate buffer- $0.1 \%$ Triton X-100 (PBT) for $1 \mathrm{~h}$ and incubated with primary antibody overnight in a rotating humidified chamber at $4^{\circ} \mathrm{C}$. The following antibodies were used (dilutions): anti S-opsin, anti ML-opsin (1:1000); anti-cone arrestin (mCAR; 1:1000); anti-cone PDE $\alpha^{\prime}$ (1:4000); anti-cone T $\alpha$ (1:500); anticone T $\gamma$ (1:500); anti-rod T $\alpha$ (UUTA; 1:1000); anti-rod PDE (MOE; $1: 1000$ ). The sections were washed in fresh changes ( $10 \mathrm{~min}$; three times) of phosphate buffer before application of the secondary antibody. Fluorescein isothiocyanate-conjugated secondary antibody raised in donkey was coapplied with propidium iodide (Invitrogen). The sections were viewed using an Olympus Fluoview (model FV 1000) inverted confocal microscope with a $60 \times, 1.3$ numerical aperture oil objective lens.

Immunoblotting. Both retinas from each mouse were isolated and added to $100 \mu \mathrm{l}$ of lysis buffer. Lysed protein (15-30 $\mu \mathrm{g} / \mathrm{lane})$ was loaded onto $4-10 \%$ Tris-glycine SDS gels, separated by electrophoresis, transferred onto polyvinylidene difluoride membrane, and probed with primary and HRP-conjugated secondary antibodies. Western Lightning (PerkinElmer) chemiluminescent substrate was used to visualize reactive bands on film.

Real-time PCR. Semiquantitative PCR was performed using total RNA from wild-type (WT), ${ }^{c} \mathrm{Kif} 3 \mathrm{a}^{+/-}$, and ${ }^{c} \mathrm{Kif} 3 \mathrm{a}^{-1-}$ retinas. The following primers were used: PDE6cqpcr2.F (5'-GCCCCTGACAGAGAAGTTGTATTTCC); PDE6cqpcr2.R (5'-ATGACCACAGCAAGGACCTCC), cTaqpcr3.F (5'-CTGTCATCTATGGGAACGTGCTGC); cTaqpcr2.R (5'-GTCCACCAACTCAGGAGGCATG); gapdhqper2.F (5'-TACCCCCAATGTGTCCGTCGTG); gapdhqpcr3.R (5'-TTGAGAGCAATGCCAGCCCC). Retinas were taken from 1-month-old mice and RNA was extracted using the RNeasy minikit (QIAGEN). RNA was reverse transcribed using random hexamers by the Superscript III First Strand Synthesis kit (Invitrogen). A validation experiment was run using fivefold dilutions of WT cDNA standards. Once amplification efficiencies were confirmed to be approximately equal, WT and mutant retinas were compared for levels of Pde6c and Gnat2 gene expression.

Electroretinography. Before recording, 2-week- or 1-month-old mice were dark adapted for $16 \mathrm{~h}$. Under dim red illumination, mice were anesthetized by intraperitoneal injection with $10 \mu \mathrm{l} / \mathrm{g}$ body weight of 10 $\mathrm{mg} / \mathrm{ml}$ ketamine and $10 \mathrm{mg} / \mathrm{ml}$ xylazine in $1 \times$ PBS. Eyes were treated with one drop of $1 \%$ tropicamide, and pupils were allowed to dilate for 15 min. A ground electrode was placed near the mouse ear, and a recording electrode was placed adjacent to the eye. ERGs were recorded using the universal testing and electrophysiological system, UTAS E-3000 (LKC Technologies). For photopic ERGs to record cone function, a rod saturating background light of $1.48 \log \mathrm{cd} \cdot \mathrm{m}^{-2}$ was used for $20 \mathrm{~min}$ before recording. Single flash responses were recorded for stimulus intensities of -0.8 to $2.9 \log \mathrm{cd} \cdot \mathrm{m}^{-2}$. Ten or fewer flashes were averaged for each intensity level with increasing flash intervals for increased intensities. For scotopic ERG, dark-adapted mice were tested for rod function at intensities ranging from -3.8 to $2.8 \mathrm{log}$ $\mathrm{cd} \cdot \mathrm{m}^{-2}$ without initial rod saturation.

Electron microscopy. Right eyes were isolated, dissected free of the anterior segments, and fixed in $2 \%$ glutaraldehyde- $1 \%$ paraformaldehyde in $0.1 \mathrm{M}$ cacodylate buffer, $\mathrm{pH} 7.4$, overnight at $4^{\circ} \mathrm{C}$. Eyes were transferred to $1 \%$ osmium tetroxide in $0.1 \mathrm{M}$ cacodylate for $1 \mathrm{~h}$, dehydrated in a series of graded methanols (Jones et al., 2003), and embedded in Eponate 12 resin (Ted Pella). The blocks were cured overnight at $65^{\circ} \mathrm{C}$. Ultrathin sections were cut at $60 \mathrm{~nm}$ and further stained with uranyl acetate and lead citrate before examination on a Hitachi $\mathrm{H}-600$ transmission electron microscope at $75 \mathrm{kV}$. Photographic negatives (Kodak EM film 4489) were scanned using an iQsmart 2 scanner (Creo; oXYgen, version 2.4.2.1) to generate digital files. When necessary to follow a cone from 
A
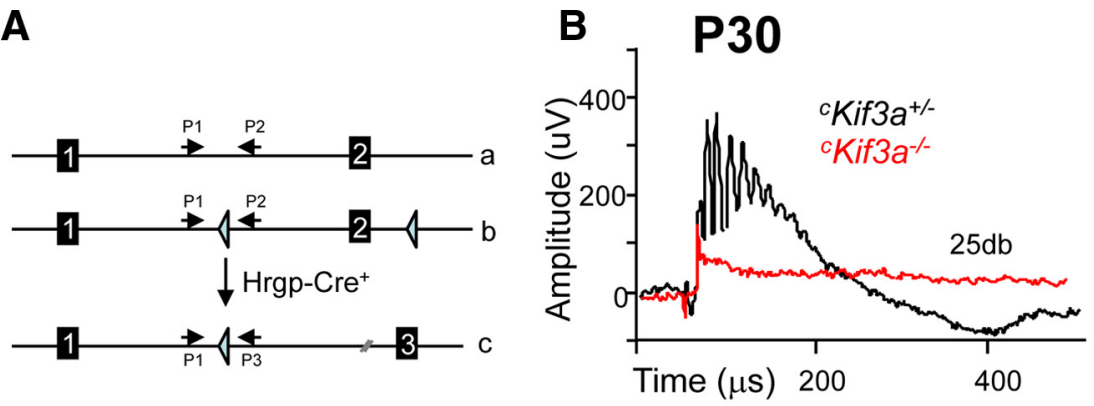

\section{C}

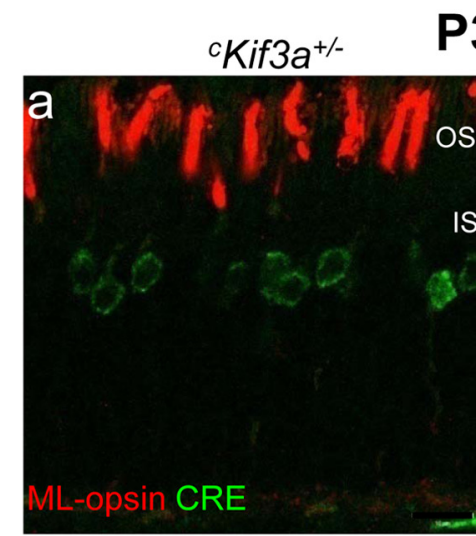

P30

${ }^{c} K i f 3 a^{-/-}$

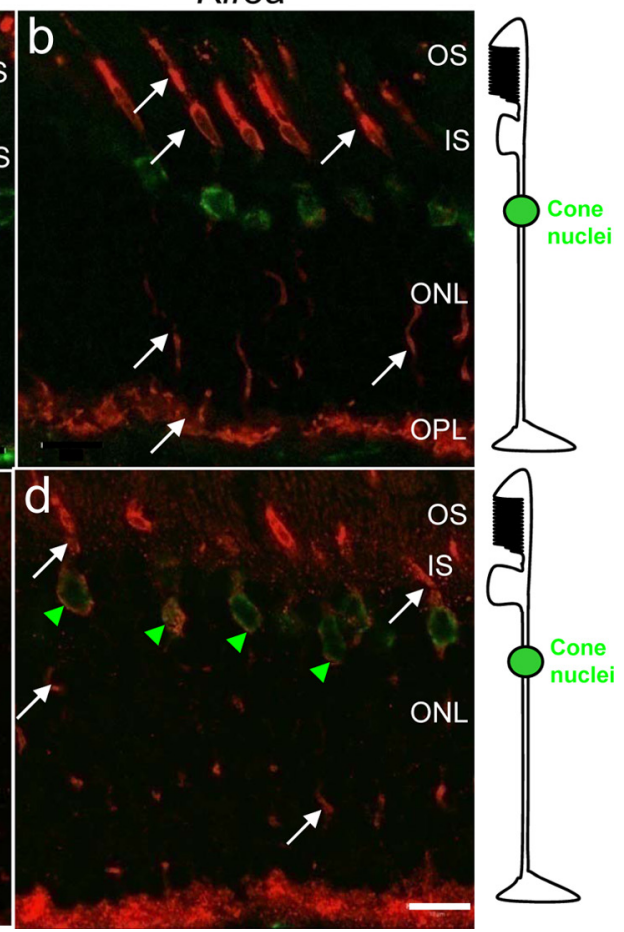

Figure 1. Generation and phenotypes of ${ }^{\mathrm{K}} \mathrm{Kif3} \mathrm{a}^{+/-}$and ${ }^{C} \mathrm{Kif3} \mathrm{a}^{-1-}$ mice. $\mathrm{A}$, Generation of cone-specific Kif3a knock-outs ( ${ }^{C}$ if $3 a^{-1-}$ ) by mating of Kif3 $a^{\text {flox /flox }}$ mice with transgenic mice expressing Cre recombinase under the control of the human $\mathrm{red} / \mathrm{green}$ opsin (Hrgp) promoter. $\boldsymbol{a}$, Diagram of exon 1 and exon 2 of the Kif3a gene; $\boldsymbol{b}$, the floxed gene; $\boldsymbol{c}$, the targeted gene with a deletion of exon 2. Primers 1-3 are used for genotyping the Kif3a alleles (Marszalek et al., 2000). B, Photopic ERG at P30. Black trace, The ${ }^{C} \mathrm{Kif3a}^{+/-}$response; red trace, the ${ }^{C} \mathrm{Kif3} \mathrm{a}^{-1-}$ response to a single flash (intensity, $25 \mathrm{db}$ or $2.9 \log \mathrm{cd} \mathrm{s} \mathrm{m}^{-2}$ ). C, Confocal immunolocalization of ML-opsin and S-opsin in cone photoreceptors of 1-month-old ${ }^{C}$ Kif3 $a^{+1-}(a, c)$ and ${ }^{C}$ Kif3a $a^{-1-}$ mice $(\boldsymbol{b}, \boldsymbol{d})$. In $\boldsymbol{a}-\boldsymbol{d}$, sections were probed with anti-Cre antibody (green); in $\boldsymbol{a}$ and $\boldsymbol{b}$, sections were probed with anti-ML-opsin (red), and in $\mathbf{c}$ and $\boldsymbol{d}$, with anti $\mathrm{S}$-opsin (red). Note that Cre recombinase is expressed in cone nuclei exclusively. ML-opsin and S-opsin are mislocalized to the inner segments, axons, and synaptic pedicles (white arrows) of ${ }^{C} \mathrm{Kif3}^{-1-}$ cones. Scale bar, $10 \mu \mathrm{m}$. IS, Inner segment; OPL, outer plexiform layer.

its nucleus through the inner segment to outer segment, digital files were tiled using Adobe Photoshop 8.0.

Semithin light-microscopic sections and silver-intensified anti-rhodopsin staining. Epon-embedded eyecups from postnatal day 14 (P14) Rho-Cre$8 ; \mathrm{Kif}_{3} \mathrm{a}^{+/++}$and Rho-Cre-8;Kif $3 a^{\text {flox/flox }}$ mice were the same as those used previously (Jimeno et al., 2006). P14 and P21 eyecups from WT littermates, iCre75+ on Kif3a flox/+ background, and iCre75+ on Kif3a flox/flox were embedded in plastic. The $200 \mathrm{~nm}$ semithin sections were arrayed on 12-spot Teflon-coated slides (Cel-Line; Erie Scientific), probed with anti-rho-1D4 IgG, and visualized with silver-intensified 1.4 $\mathrm{nm}$ gold granules conjugated to goat anti-mouse IgG (Nanoprobes). All data were captured as 8 bit 1388 pixel $\times 1036$ line frames under voltageregulated tungsten halogen flux with a variation of $1.2 \pm 0.6 \%$ per minute (mean $\pm \mathrm{SD})$. Image mosaic tiles were captured with a Peltiercooled QImaging Fast 1394 QICAM (QImaging) and a Syncroscan montaging system (Synoptics) on a Scan $100 \times 100$ stage (Märzhäuser Wetzlar).

\section{Results}

Cones lacking KIF3A are nonfunctional We generated ${ }^{c} \mathrm{Kif} 3 \mathrm{a}^{+/-}$(short for $\mathrm{Kif} 3 \mathrm{a}^{\text {flox } / W T} ; \mathrm{Hrgp}-\mathrm{Cre}{ }^{+}$) and ${ }^{c} \mathrm{Kif} 3 a^{-1-}$ (short for Kif $3 a^{\text {flox } / \text { flox }} ; \mathrm{Hrgp}-\mathrm{Cr} \mathrm{C}^{+}$) mice by mating heterozygous or homozygous floxed Kif3a mice (Marszalek et al., 2000) with transgenic mice expressing Cre recombinase under the control of a human red/green pigment ( $H r g p$ ) gene promoter (Hrgp-Cre ${ }^{+}$) (Le et al., 2004) (Fig. 1A). To study the consequences of Kif $3 a$ deletion in cones, we tested ${ }^{c} \mathrm{Kif} 3 \mathrm{a}^{-1-}$ and ${ }^{c} \mathrm{Kif} 3 a^{+/-}$mice for cone photoreceptor function by photopic ERG (under rodsaturating background light). Control ${ }^{c} \mathrm{Kif3} \mathrm{a}^{+/-}$mice showed ERG responses comparable with those of wild-type mice, whereas P14 (supplemental Fig. S3A, available at www.jneurosci.org as supplemental material) and $\mathrm{P} 30{ }^{c} \mathrm{Kif} 3 \mathrm{a}^{-1-}$ mice (Fig. $1 B$ ) showed no response, suggesting the absence of key phototransduction components or cone degeneration.

\section{Cone visual pigments mislocalize in Kif3a-deleted cones}

We next tested the photoreceptors of 1-month-old mice for expression of Cre recombinase and subcellular localization of cone pigments by immunocytochemistry (Fig. 1C; supplemental Fig. $\mathrm{S} 1$, available at www.jneurosci.org as supplemental material). As expected, Cre recombinase was detected exclusively in the nuclear and perinuclear region of cones (Fig. 1C, green) (Le et al., 1999). Nearuniform Hrgp-driven expression in cone nuclei was observed using a Cre-activatable $L a c Z$ reporter mouse line (ROSA26) (Le et al., 2004), consistent with M/L-opsin being expressed in nearly all mouse cones (Applebury et al., 2000; Haverkamp et al., 2005). In ${ }^{c} \mathrm{Kif}_{3} a^{-1-}$ cones, ML-opsin (white arrows in Fig. $1 C b$; supplemental Fig. S1b, available at www.jneurosci.org as supplemental material) and S-opsin (white arrows in Fig. 1Cd; supplemental Fig. S1d, available at www.jneurosci.org as supplemental material) mislocalize indiscriminately to cone inner and outer segments, to the axons, and synaptic pedicles, suggesting lack of targeted transport to the outer segments. S-opsin appears more susceptible to Kif3a knockdown than ML-opsin, similarly as observed in Rpe65 $5^{-1-}$ and $\mathrm{Lrat}^{-1-}$ cones (Zhang et al., 2008). Cre recombinase and S-opsin colocalize in perinuclear locales (presumably endoplasmic reticulum), suggesting aberrant export of S-opsin from the ER (Fig. 1C, green arrowheads). The distribution of opsins in endomembranes suggests indiscriminate deposition and nontargeted transport or diffusion (see Discussion). In ${ }^{c} \mathrm{Kif}_{3} \mathrm{a}^{+/-}$cones (Fig. $1 \mathrm{Ca}, \mathrm{c}$ ), transport of ML-opsin and S-opsin to the mutant COS proceeds normally, indicating that deletion of only one Kif3a allele has little, if any, consequence. 
In transgenic $\mathrm{Hrgp}-\mathrm{Cre}^{+}$mice placed on the ROSA26 background, Cremediated recombination was first observed between P7 and P10 (Le et al., 2006). At 2 weeks of age, we observed prominent Cre expression in ${ }^{c} \mathrm{Kif} 3 \mathrm{a}^{+/-}$ and ${ }^{c} \mathrm{Kif} 3 \mathrm{a}^{+/-}$retinas (supplemental Fig. S2, red signal, available at www.jneurosci. org as supplemental material). In superior (supplemental Fig. S2b, available at www. jneurosci.org as supplemental material) and inferior (supplemental Fig. S2c, available at www.jneurosci.org as supplemental material) regions of homozygous knock-out retinas, $\mathrm{M} / \mathrm{L}$-opsin levels in the COS are clearly reduced, but cone degeneration, as judged from labeling with antimouse cone arrestin antibody (mCar) (Fig. $1 C b$; supplemental Fig. S2 $b$, available at www.jneurosci.org as supplemental material), is at a very early stage, suggesting that mislocalization of pigments precedes degeneration. Mislocalization of $\mathrm{M} / \mathrm{L}-\mathrm{opsin}$ and cone degeneration proceeds more strongly in the inferior ${ }^{c} \mathrm{Kif}_{3} \mathrm{a}^{-1-}$ retina (supplemental Fig. S2i,l,o, available at www.jneurosci.org as supplemental material) than in the superior ${ }^{c} \mathrm{Kif}_{3} a^{-1-}$ retina (supplemental Fig. S2 $h, k, n$, available at www.jneurosci.org as supplemental material) over a time course of 16 weeks. Remnants of $\mathrm{M} / \mathrm{L}$-opsin are still detectable at 16 weeks in the superior (supplemental Fig. S2n, available at www. jneurosci.org as supplemental material), but not inferior ${ }^{c} \mathrm{Kif} 3 \mathrm{a}^{-1-}$ retina (supplemental Fig. S2o, available at www. jneurosci.org as supplemental material).

\section{Mistargeting of membrane-associated proteins in ' $\mathrm{Kif3} \mathrm{a}^{-1-}$ cones}

We were particularly interested in whether deletion of KIF3A affects the subcellular localization of membrane-associated proteins [peripheral membrane proteins (PMPs)] (cone transducin and PDE6, GRK1) that require vesicular transport as has been observed for prenylated RAS (Choy et al., 1999) and heterotrimeric G-proteins (Michaelson et al., 2002). Membrane association is mediated by C-terminal prenylation (rod and cone $\mathrm{T} \gamma$, rod and cone PDE6 catalytic subunits, GRK1) or N-terminal acylation (rod and cone $\mathrm{T} \alpha$ ). After biosynthesis, prenylated phototransduction proteins dock to the ER and traffic by vesicular transport to the outer segments (Zhang et al., 2007; Karan et al., 2008), In P30 ${ }^{c} \mathrm{Kif} 3 \mathrm{a}^{+/-}$cones, PMPs are properly localized to COS in which phototransduction occurs (Fig. $2 \mathrm{Aa}, \mathrm{c}, e, g)$, but are undetectable in ${ }^{c} \mathrm{Kif}_{3} \mathrm{a}^{-1-} \mathrm{COS}$ and/or mislocalized throughout the inner segments (Fig. $2 A b, d, f, h$ ). Cone $\mathrm{PDE} \alpha^{\prime}$ and cone $\mathrm{T} \gamma$ were also undetectable at P14 in ${ }^{c} \mathrm{Kif} 3 a^{-1-}$

B

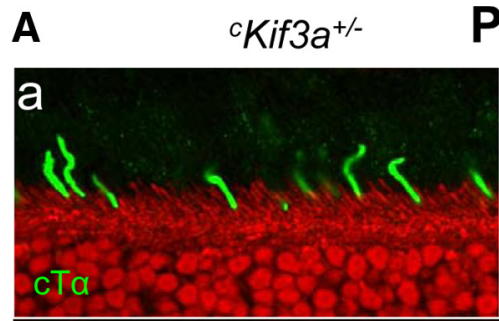

P30 ${ }^{c} \mathrm{Kif3} \mathrm{a}^{-/-}$

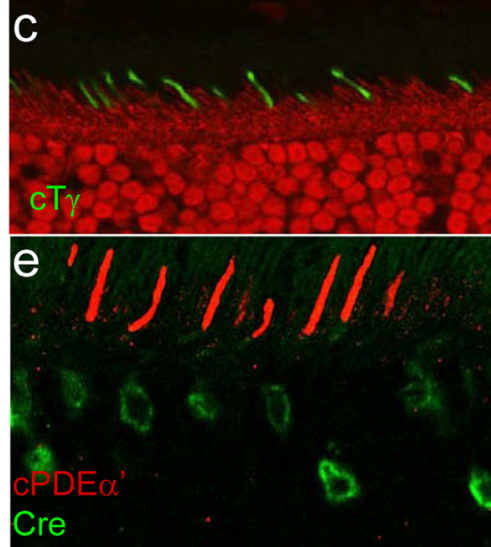

b
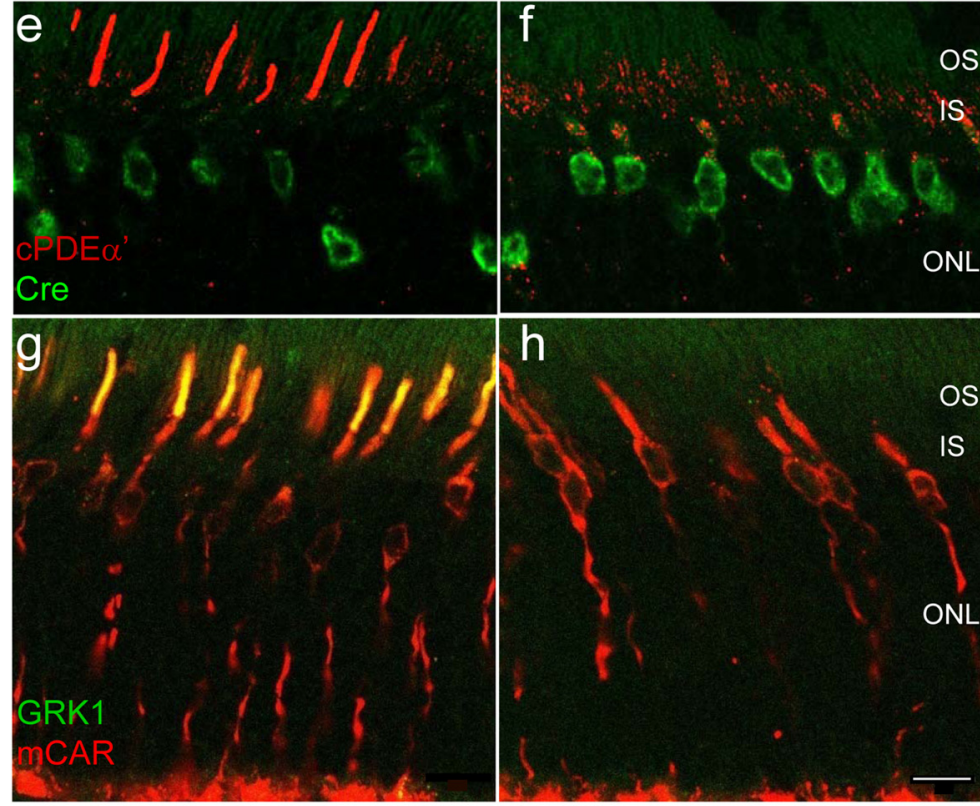

-olm
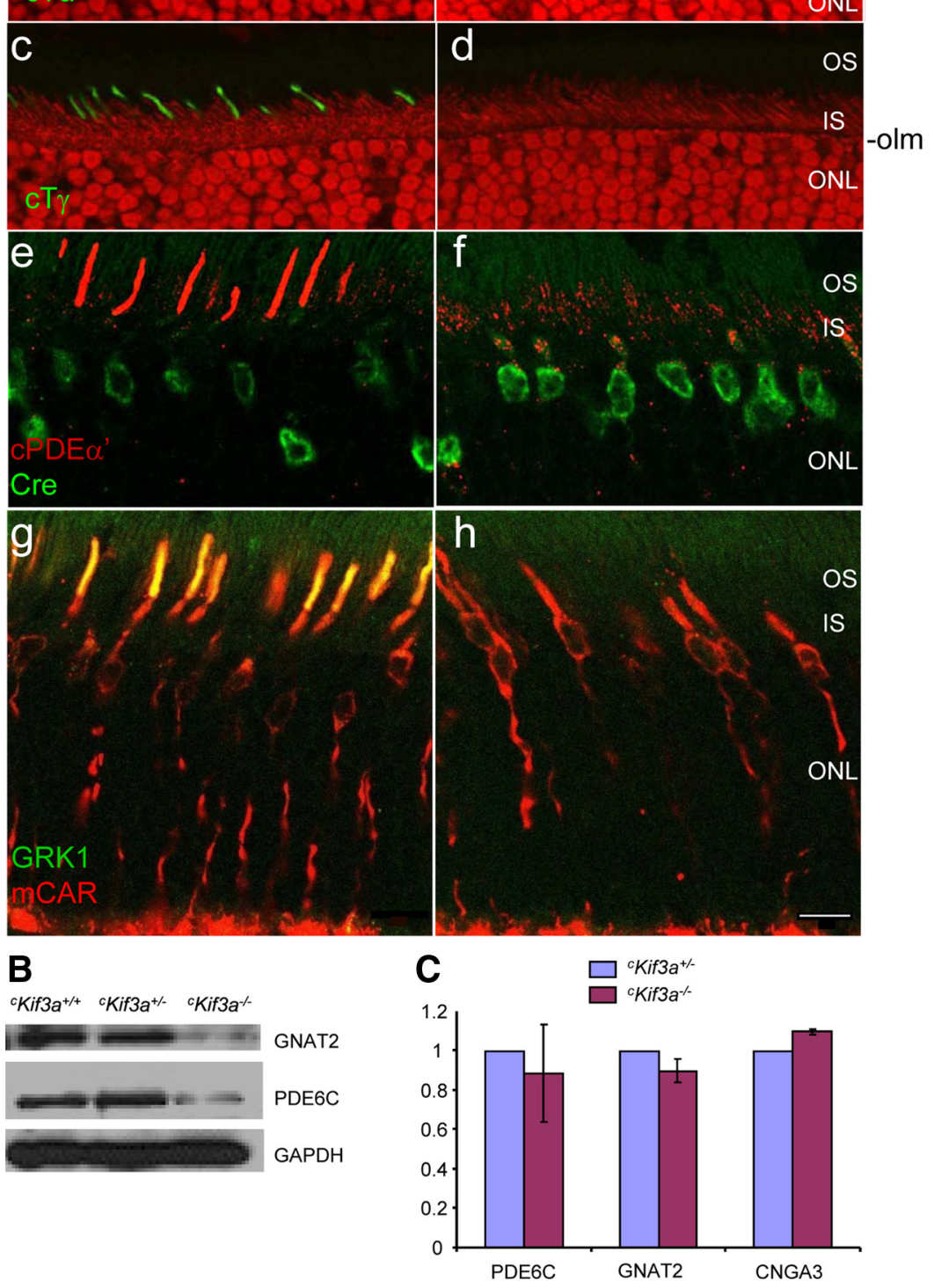

Figure 2. Immunolocalization of cone $\mathrm{T} \alpha, \mathrm{T} \gamma$, PDE $6 \alpha^{\prime}$, GRK1, and mCar in ' $K$ if3 $a^{+/-}$and ' $K$ if3 $a^{-l-}$ cones. A, Frozen sections were probed with either anti-cone T $\alpha$ (green; $\boldsymbol{a}, \boldsymbol{b})$, anti-cone T $\gamma(\mathrm{green} ; \boldsymbol{c}, \boldsymbol{d})$, anti-cone PDE6 $\alpha^{\prime}$ (red; $\left.\boldsymbol{e}, \boldsymbol{f}\right)$, or anti-GRK1 (green; $\left.\boldsymbol{g}, \boldsymbol{h}\right)$ antibodies. Some sections were contrasted with propidium iodide (red) to define the outer limiting membrane $(0 / m)$ and the inner segments $(\boldsymbol{a}-\boldsymbol{d})$. Note the normal distributions of cone T $\alpha$, cone T $\gamma$, and cone PDE $6 \alpha^{\prime}$ in 'Kif3a ${ }^{+/-} \operatorname{COS}$, but absence $(\boldsymbol{b}, \boldsymbol{d}, \boldsymbol{h})$ or mislocalization to the inner segments $(\boldsymbol{f})$ of ${ }^{C} \mathrm{Kif3} a^{-/-}$cones. In contrast, sections $(\boldsymbol{g}, \boldsymbol{h})$ probed simultaneously with antibodies directed against cone arrestin (mCAR; red) and anti-GRK1 (green) revealed that cone arrestin distributes freely in $\mathrm{Kif3a}^{+/-}$and $\mathrm{Kif3}^{-/-}$cones. Cone arrestin and GRK1 colocalize (yellow; $\boldsymbol{g}$ ) in $0 \mathrm{~S}^{\mathrm{C}} \mathrm{Kif3}^{+/-} \mathrm{C}^{+-}$, but not ${ }^{\mathrm{C}} \mathrm{Kif3} \mathrm{a}^{-1-}$ cones. IS, Inner segments. Scale bars, $10 \mu \mathrm{m}$. $B$, Immunoblots of $\mathrm{Kif3a}^{+/-}$, and 'Kif3a ${ }^{-1-}$ retina lysates probed with anti-cone $\mathrm{T} \alpha$, and anti-cone PDE $6 \alpha$ ' antibodies. In each immunoblot, GAPDH was included as an internal control. Note cone transducin and PDE $6 \alpha$ ' subunit levels are reduced in $\mathrm{Kif3}^{-1-} . \mathrm{C}$, Semiquantitative real-time RT/PCR of cone Pde6a (PDE6 $\alpha{ }^{\prime}$ ), Gnat2 (cone T $\alpha$ ), and Cnga3 mRNA of 'Kif3a ${ }^{+/-}$and 'Kif3a ${ }^{-/-}$retinas. Each sample was determined in duplicate from two retinas of different animals of the same genotype. PCRs were run in parallel with Gapdh-specific primers as a standard. Note that mRNA levels are unaffected. Scale bar, $10 \mu \mathrm{m}$.

COS (supplemental Fig. S3B, available at www.jneurosci.org as supplemental material). The soluble cone arrestin is unaffected by KIF3A deletion and diffuses freely (Fig. $2 \mathrm{Ag}, h$ ). Immunoblots confirmed a significant decrease in cone T $\alpha$ and cone PDE6 $\alpha^{\prime}$ 


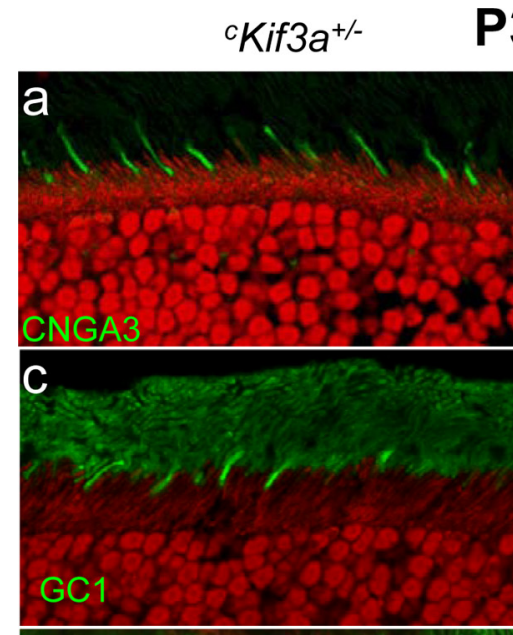

\section{P30}
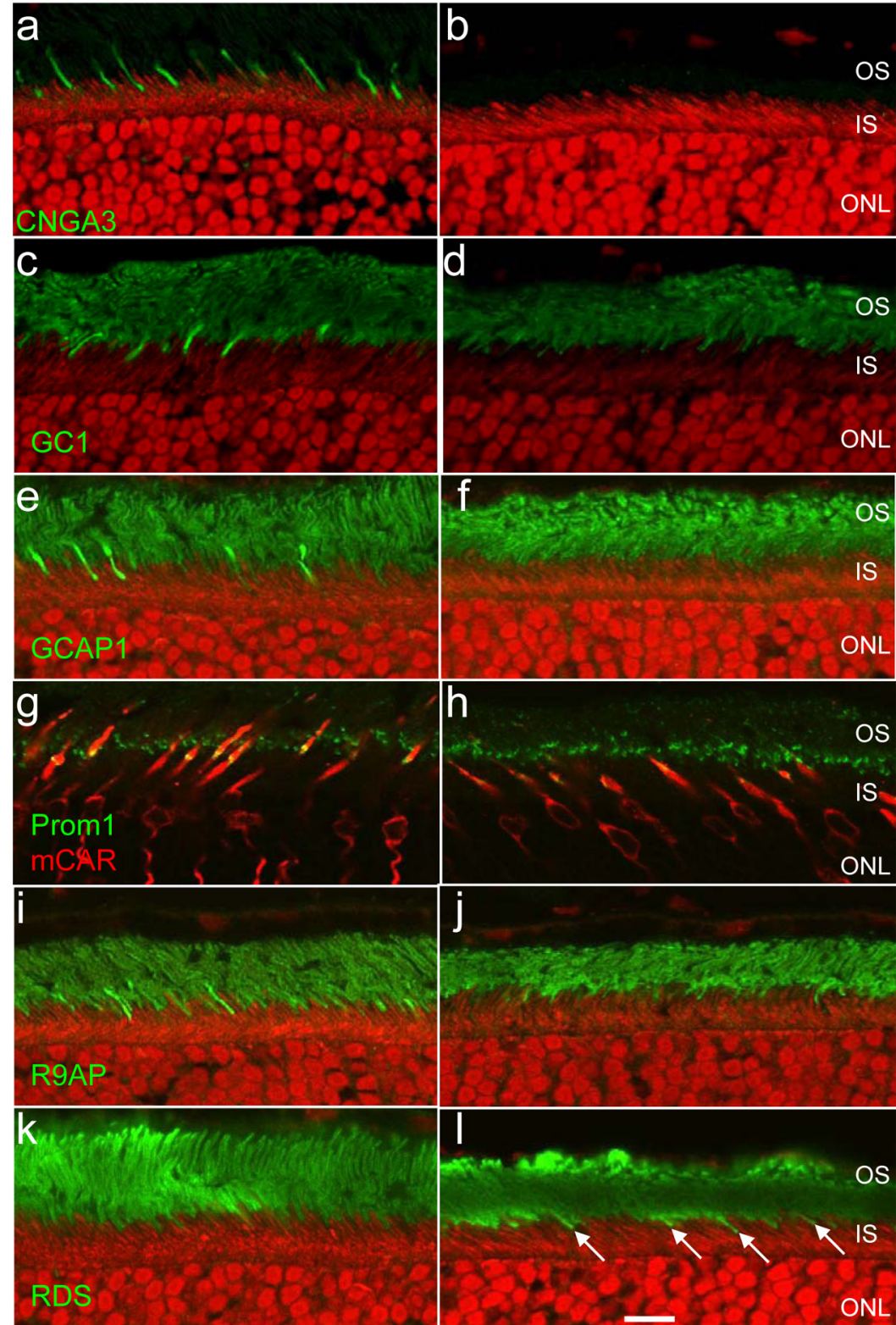
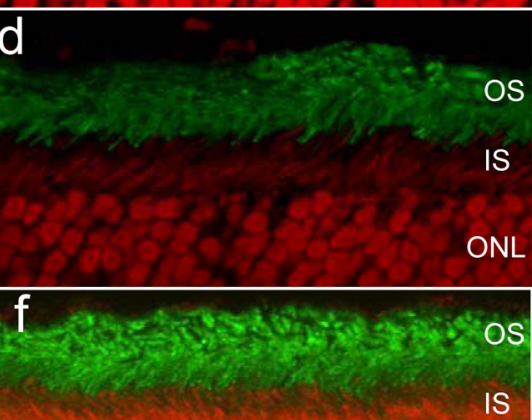

IS
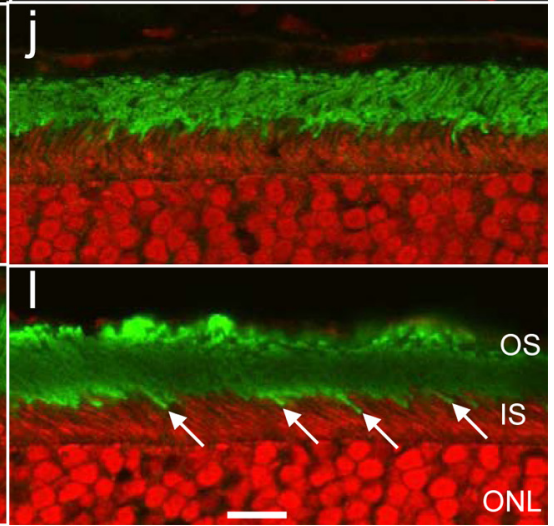

Figure 3. Distribution of outer segment membrane proteins in P30 Kif3a-deleted cones. Sections of ${ }^{C} K_{i f 3 a}{ }^{+/-}(\boldsymbol{a}, \boldsymbol{c}, \boldsymbol{e}, \boldsymbol{g}, \boldsymbol{i}, \boldsymbol{k})$ and ${ }^{C} K i f 3 a^{-/-}$retinas $(\boldsymbol{b}, \boldsymbol{d}, \boldsymbol{f}, \boldsymbol{h}, \boldsymbol{j}, \boldsymbol{I})$ were probed with antibodies recognizing $\operatorname{CNGA3}(\boldsymbol{a}, \boldsymbol{b}), \mathrm{GC} 1(\boldsymbol{c}, \boldsymbol{d}), \operatorname{GCAP} 1(\boldsymbol{e}, \boldsymbol{f})$, prominin-1 $(\boldsymbol{g}, \boldsymbol{h}), \operatorname{R9AP}(\boldsymbol{i}, \boldsymbol{j})$, and peripherin/rds $(\boldsymbol{k}, \boldsymbol{I})$. Antigen localizations are visualized using FITC-conjugated secondary antibody (green). The ONL of some sections was contrasted with propidium iodide $(\boldsymbol{a}-\boldsymbol{f}, \boldsymbol{i}-\boldsymbol{I})$, whereas in other sections, cone cells were identified with anti-cone arrestin ( $\mathrm{red} ; \boldsymbol{g}, \boldsymbol{h})$. Note that, in ${ }^{\mathrm{C}} \mathrm{Kif3} \mathrm{a}^{-1-}$ cones, membrane proteins were severely reduced or completely absent, with the exception of peripherin/rds (I, arrows). Scale bar, $10 \mu \mathrm{m}$.

protein levels (Fig. $2 B$ ). GRK1 and GCAP1 did not show decreased protein levels (data not shown) since they are expressed also in unaffected rods, which represent the majority (95-97\%) of photoreceptors in the mouse retina. Real-time quantitative PCR with ${ }^{c} \mathrm{Kif} 3 a^{-l-}$ and ${ }^{c} \mathrm{Kif} 3 a^{+/-}$retina mRNA templates confirmed that there was no significant change in expression levels of Gnat2 (cT $\alpha)$, Pde6c (cPDE6 $\left.\alpha^{\prime}\right)$, and Cnga3 mRNA, suggesting that the decreased protein levels in ${ }^{c} \mathrm{Kif}_{3} \mathrm{a}^{-1-}$ retinas are attributable to posttranslational degradation (Fig. 2C). Deletion of KIF3A in cones thereby results in deficient transport of outer segment PMPs, consistent with the notion that heterotrimeric kinesin-II powers their anterograde IFT through cone cilia.
We further investigated the effect of KIF3A deletion on trafficking of integral membrane proteins that participate in phototransduction (opsins, CNGA3, GC1, and R9AP), or are involved in disc morphogenesis (peripherin/rds, prominin-1) (Fig. 3). CNGA3 (the cGMP-gated channel $\alpha$-subunit) (Kaupp and Seifert, 2002), GC1 (an enzyme producing cGMP, the transmitter in phototransduction) (Baehr et al., 2007), and R9AP (the membrane anchor of the GTPase-activating protein complex) (Hu and Wensel, 2002) are transmembrane proteins that, like the visual pigments, postsynthetically follow the pathway from the ER to the Golgi/ TGN and plasma membrane. Only CNGA3 is cone specific (Fig. $3 a$ ), whereas GC1, GCAP1, R9AP, and peripherin/rds are expressed in both rods and cones (Fig. $3 c, e, i, k)$. Confocal immunolocalization shows that cone-specific deletion of KIF3A prevents trafficking of CNGA3, GC1, GCAP1, R9AP to cone outer segments (Fig. 3b, $d, f, j$ ). Peripherin/rds (Fig. $3 k$ ), in contrast, apparently trafficked normally, suggesting that this tetraspanning glycoprotein is not cargo in IFT powered by kinesin-II. Peripherin/rds was shown previously to transport to the outer segments independently from rhodopsin in BBS2-null (Nishimura et al., 2004) and rhodopsin mutant mice (Green et al., 2000; Lee et al., 2006). Prominin-1 is expressed ubiquitously and in photoreceptors typically associated with plasma membrane protrusions (Jászai et al., 2007; Kleinman and Ambati, 2008), and localizes in retina specifically to cilia of WT (Yang et al., 2008) and ${ }^{c} \mathrm{Kif}_{3} \mathrm{a}^{+/-}$rods and cones (Fig. 3g). At ${ }^{c} \mathrm{Kif} 3 a^{-1-}$ cilia, however, prominin-1 levels are much reduced (Fig. $3 h$ ).

\section{Ultrastructure of ${ }^{c} \mathrm{Kif} 3 \mathrm{a}^{-/-}$cone outer segments}

To determine the effect of KIF3A deletion on COS fine structure, $60-\mathrm{nm}$-thin sections of $\mathrm{P} 13{ }^{c} \mathrm{Kif} 3 \mathrm{a}^{-1-}$ retina, taken in the central retina inferior to the optic nerve, were analyzed by electron microscopy (Fig. 4). The P13 time point, $1 \mathrm{~d}$ after eye opening, was chosen to capture structural deficiencies before massive degeneration. Cones were identified by large oval nuclei containing a clump of finely granular heterochromatin and, occasionally, an osmiophilic droplet in the inner segment (supplemental Fig. S4, white arrow, available at www.jneurosci.org as supplemental material); rod nuclei, in contrast, were much more electron dense. Cone outer segments were observed in various stages of degeneration with membrane layers found in both perpendicular and parallel orientations as well as in whorls (Fig. $4 a-c)$. Connecting cilia of affected cones appeared to have normal structures proximally, suggesting that KIF3A is not required for ciliary maintenance at P13. However, overlapping disc cas- 
cades (Fig. 4d,e, between white arrows) and longitudinally aligned membranes were sometimes observed at the distal end of connecting cilia of early degenerating cones. ${ }^{c} \mathrm{Kif} 3 \mathrm{a}^{-1-}$ cone inner segments contained distended Golgi apparati and mitochondria typically characterized by a pale matrix with irregularly arranged cristae (Fig. $4 d, f, \mathrm{~m}_{\mathrm{c}}$ ). Whereas inner and outer segments showed obvious signs of dysfunction, cone pedicles remained vesicle-laden with multiple, small synaptic contacts (supplemental Fig. S5, white arrows, available at www.jneurosci.org as supplemental material).

\section{Consequences of KIF3A deletion in rods}

To investigate the fate of PMPs in KIF3Adeleted rods, we generated rod-specific deletions of KIF3A ${ }^{r}{\mathrm{Kif} 3 a^{+/-}}$and ${ }^{r} \mathrm{Kif}_{3} \mathrm{a}^{-1-}$ mice) following the strategy depicted in Figure $1 A$, using transgenic mice expressing Cre recombinase under the control of a $4.4 \mathrm{~kb}$ mouse opsin promoter (iCre $75^{+}$line) (Li et al., 2008). Previously generated rod Kif3a knock-outs (Marszalek et al., 2000; Jimeno et al., 2006), using another Cre expressor line (Rho-Cre-8), showed a rapidly progressing degeneration starting around P10 accompanied by apparent rhodopsin mistargeting. Scotopic (dark-adapted) ${ }^{r} \mathrm{Kif}_{3} \mathrm{a}^{+/-}$and ${ }^{r} \mathrm{Kif}_{3} \mathrm{a}^{-1-}$ electroretinograms recorded at P14 reveal that the ${ }^{r}$ Kif $3 a^{-1-}$ a-wave amplitudes are reduced, suggesting compromised rod function and degeneration (Fig. 5A). The diagnostic fragment generated by the deletion of exon 2 and portions of adjacent introns (Fig. $5 B$, del) is easily detectable at P14 and signals early expression of Cre in rods. However, as judged by immunoblots (Fig. 5C) and the normal thickness of the P14 ${ }^{r} \mathrm{Kif} 3 \mathrm{a}^{-1-}$ outer nuclear layer (ONL) (Fig. 5Dc,f), rod degeneration is at an early stage.

At this age, Cre recombinase was expressed uniformly in all ${ }^{r} \mathrm{Kif} 3 \mathrm{a}^{-1-}$ nuclei (Fig. 5Dc,f), and KIF3A was essentially undetectable in rod cells. Cone nuclei, in contrast, did not express Cre (white arrows) consistent with specificity of the mouse rhodopsin promoter, and KIF3A is detectable in cone cell bodies. As clearly shown in Figure 5Df, the bulk of rhodopsin trafficked to the outer segments in the absence of KIF3A, suggesting an alternate motor for rod transport. Confocal immunolocalization of additional photoreceptor-specific proteins (Fig. 6, right column) indicates that the integral membrane proteins CNGA1 (rod CNG channel $\alpha$-subunit) (Fig. 6a,b), GC1 (Fig. $6 c, d$ ), R9AP (Fig. $6 e, f$ ), and Prominin 1 (Fig. $6 g, h$ ) also localize correctly in
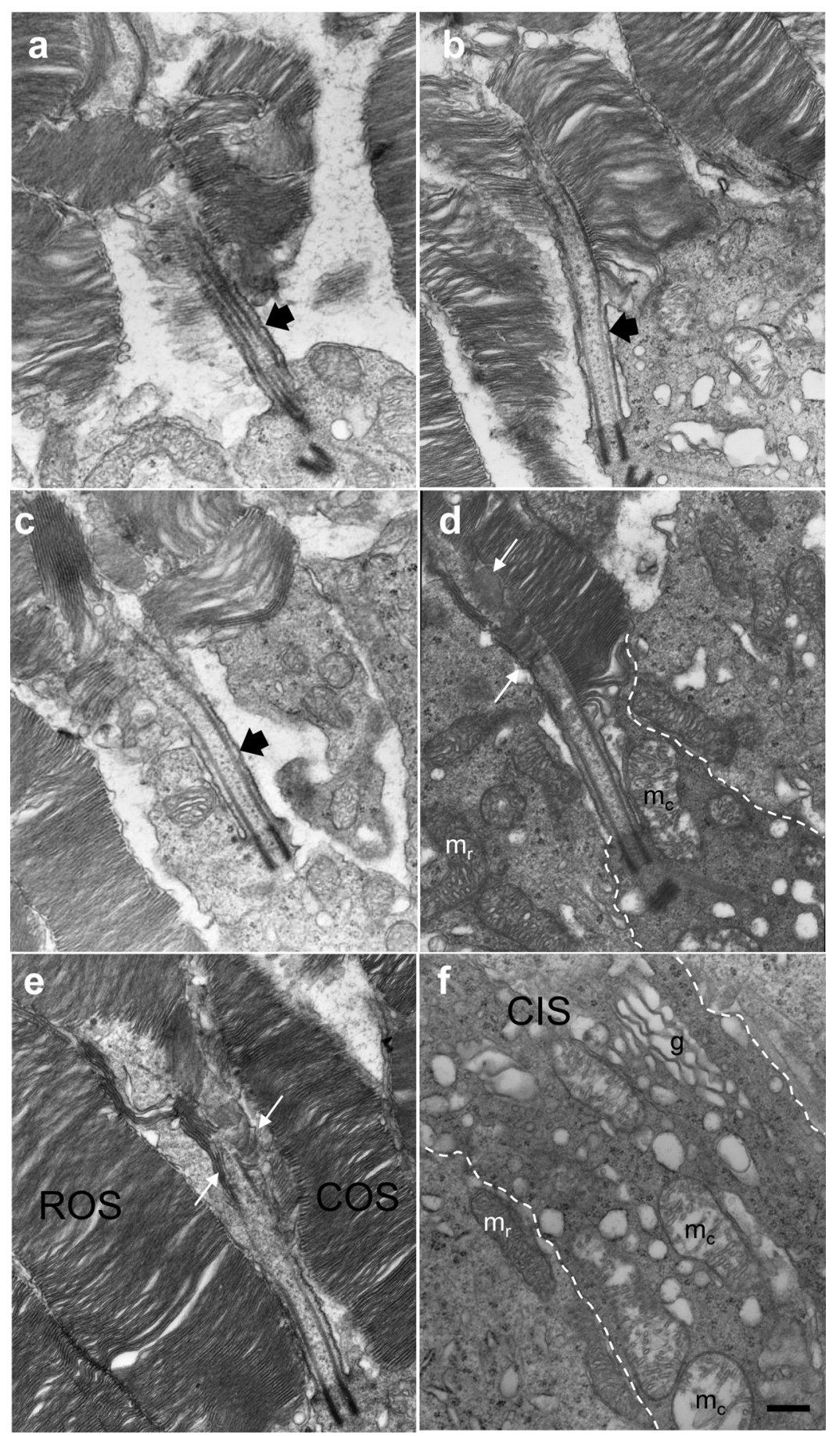

Figure 4. Fine structure of Kif3a-deleted cones at postnatal day 13. Proximal COSs reveal that connecting cilia (black arrows; $\boldsymbol{a}-\boldsymbol{c}$ ) develop, although outer segment membranes appear misaligned. Misalignment was most severe in cones inferior to the optic nerve, and less severe in cones located in the superior midperiphery. Examples of COSs found in various stages of membrane disorganization: $\boldsymbol{a}$, immediately inferior to the optic nerve and advanced; $\boldsymbol{b}, \boldsymbol{c}$, intermediate; and $\boldsymbol{d}, \boldsymbol{e}$, early in degeneration. The plasma membrane (dashed white line; $\boldsymbol{d}, \boldsymbol{f}$ ) defines the extent of the distal cone inner segment (CIS), in which cone mitochondria $\left(m_{c}\right)$ with disrupted cristae were distinct from rod mitochondria $\left(m_{r}\right)$. A cascade of five to seven overlapping membrane discs appears at the expanded axoneme (between pair of white arrows; $\boldsymbol{d}, \boldsymbol{e}$ ). More proximally, in a ${ }^{C} \mathrm{Kif3} a^{-1-}$ cone inner segment ( $\boldsymbol{f}$, between dashed white lines), vesicles of heterogeneous diameter were dispersed among mitochondria $\left(m_{c}\right)$ and a Golgi apparatus. Scale bar, $0.2 \mu \mathrm{m}$ (for $\boldsymbol{a}-\boldsymbol{f}$ ).

P14 ${ }^{r} \mathrm{Kif}_{3 a^{-1-}}$ rods. Furthermore, the PMPs PDE6 (all subunits) (Fig. 6i,j), rod T $\alpha$ (Fig. 6k,l), and GRK1 (Fig. 6m,n) traffic normally to rod outer segments in both ${ }^{r} \mathrm{Kif}_{3} \mathrm{a}^{-1-}$ and ${ }^{r} \mathrm{Kif}_{3} \mathrm{a}^{+/-}$photoreceptors. 


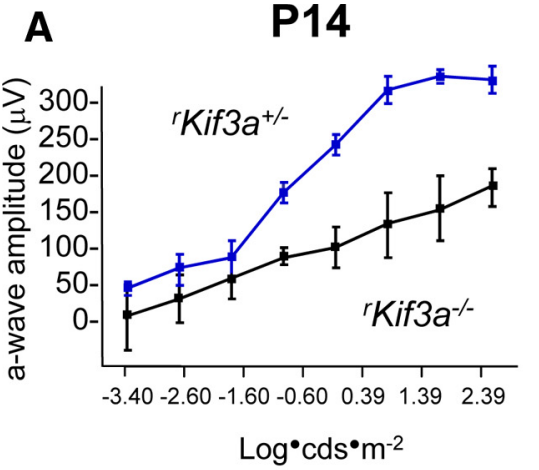

B

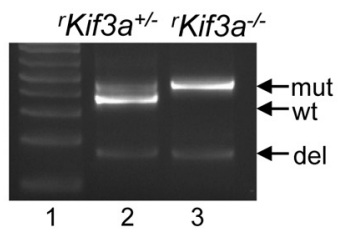

C

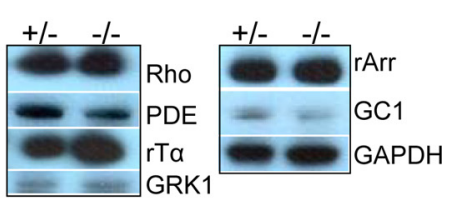

D WT littermate
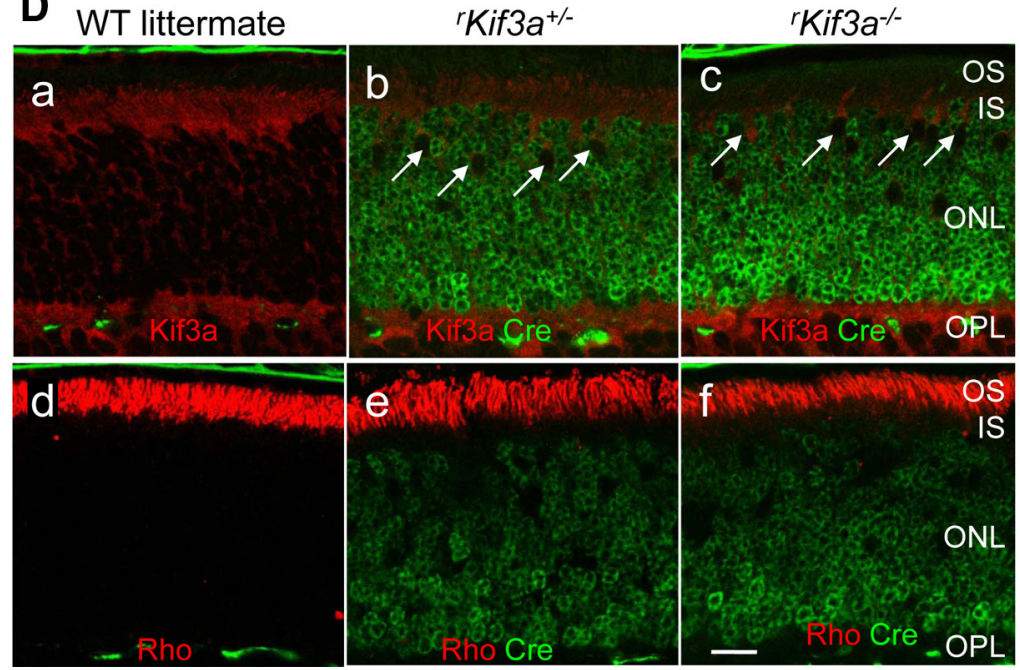

Figure 5. KIF3A deletion in P14 rod photoreceptors. $\boldsymbol{A}$, Scotopic (dark-adapted) electroretinogram of P14 ${ }^{r} \mathrm{Kif3}^{+}{ }^{+/-}$and ${ }^{r} \mathrm{Kif3}^{-1-}$ mice. The ${ }^{r} \mathrm{Kif3} a^{-1-}$ a-wave amplitude, indicative of rod function, is attenuated relative to the WT a-wave response at all intensities tested. Error bars indicate SEM. B, PCR-based genotyping of ${ }^{r} K_{i f 3} a^{+/-}$(lane 2) and ${ }^{r} K_{i f 3} a^{-1-}$ mice (lane 3) with primers $\mathrm{P} 1, \mathrm{P} 2$, and $\mathrm{P} 3$ and retina DNA as a template (see Materials and Methods) (Fig. $1 \mathrm{~A}$ ). P1 and P2 amplify the WT fragment (wt) and the mutant (insertion of loxP) fragment (mut) from ${ }^{r} \mathrm{Kif3}^{+/-} \mathrm{DNA}$, but only the mutant fragment from ${ }^{r} \mathrm{Kif}^{+} a^{-1-}$ DNA. P1 and P3 amplify the deletion fragment (del) appearing after excision of exon 2. Both the heterozygous and homozygous floxed mice show the deletion fragment at P14. Lane 1, MW standards. C, Immunoblots. Polypeptides of ${ }^{r} K_{i f 3} a^{+/-}$and $^{r} K_{i f 3} a^{-1-}$ retina lysates were separated by SDS-PAGE, blotted, and probed with anti-rhodopsin, anti-rod T $\alpha$, anti-rod PDE6, anti-GRK1, anti-rod arrestin, and anti-GC1. Anti-GAPDH served as a loading control. Note that the proteins levels are very similar in both from ${ }^{r} K_{i f 3} a^{+/-}(+/-)$and $^{r}$ Kif3a $a^{-1-}(-/-)$ lanes. D, Confocal immunolocalization of KIF3A and rhodopsin in P14 littermate WT $(\boldsymbol{a}, \boldsymbol{d}),{ }^{r} K_{i f 3} a^{+/-}(\boldsymbol{b}, \boldsymbol{e})$, and ${ }^{r} K i f 3 a^{-I-}(\boldsymbol{c}, \boldsymbol{f})$ cryosections imaged in the midperiphery. Retina sections were probed simultaneously with anti-Cre recombinase monoclonal antibody (green; $\boldsymbol{b}, \boldsymbol{c}, \boldsymbol{e}, \boldsymbol{f}$ ) and either anti-KIF3A (red; $\boldsymbol{a}-\boldsymbol{c}$ ) or anti-rhodopsin (red; $\boldsymbol{d}-\boldsymbol{f})$ polyclonal antibody. The white arrows $(\boldsymbol{b}, \boldsymbol{c})$ indicate examples of cone nuclei that do not express Cre recombinase. KIF3A is essentially undetectable in ${ }^{r} \mathrm{Kif3} a^{-1-}$ rod inner segments but present in cone inner segments, which are unaffected by the rod-specific deletion. Note prominent immunolabel for rhodopsin over ${ }^{r} \mathrm{Kif3}^{-1-}$ rod outer segments that are reduced in length relative to WT. Several pyknotic nuclei were observed in the proximal ${ }^{r} K i f 3 a^{-1-}$ ONL. Scale bar: $\boldsymbol{a}-\boldsymbol{f}, 10 \mu \mathrm{m}$.

(Fig. 8f), now accumulate in the perinuclear region, likely because of degeneration. At this late stage, only remnants of rhodopsin-containing membranes are detectable (Fig. $8 b$ ). We conclude that rod degeneration in the ${ }^{r} \mathrm{Kif} 3 \mathrm{a}^{-1-}$ retina begins before P14, as judged by ERG (Fig. $5 A$ ), and proceeds rapidly between P14 and P28. Although the mechanism triggering cell death remains undefined, the most obvious phenotypic observation at P14 is absence of KIF3A, the obligatory motor subunit of heterotrimeric kinesin-II.

\section{Deletion of KIF3A in rods and cones does not impair trafficking of a subset of synaptic proteins}

KIF3A is localized throughout the photoreceptor cell and has been previously shown to be present at the ribbon synapse (Muresan et al., 1999). To determine whether anterograde transport of synapsespecific proteins were affected in Kif $3 A$ cone-specific knock-outs, ${ }^{c}$ Kif $3 a^{+/-}$and ${ }^{c} \mathrm{Kif} 3 \mathrm{a}^{-1-}$ retina sections were labeled with antibodies against proteins specifically located in synaptic terminals. The results (Fig. 9A) show that bassoon (tom Dieck et al., 1998; Sanmartí-Vila et al., 2000), ribeye (Schmitz et al., 2000), PSD95, a protein associated with MPP4 (Yang et al., 2007), cone-specific complexin-III (Reim et al., 2005), UNC119/RG4 (Kobayashi et al., 2003; Haeseleer, 2008), and synaptic vesicle protein SV2 (Heidelberger et al., 2005) localize normally in P28 ${ }^{c} \mathrm{Kif} 3 \mathrm{a}^{-1-}$ cone synaptic pedicles. Parallel experiments were performed with rod-specific KIF3Adeleted sections. Trafficking of ribeye, SV2 protein, rod-specific complexin IV (CPXIV), bassoon, and UNC119/HRG4

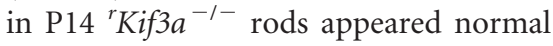
(Fig. 9B). We conclude that ribbonassociated proteins and at least one SNARE (soluble $N$-ethylmaleimide-sensitive factor attachment protein receptor) complex binding protein transport properly to rod

Immunocytochemical analysis of ${ }^{r} \mathrm{Kif}_{3} \mathrm{a}^{-1-}$ rods at P21 (Fig. 7) revealed no mistargeting of rhodopsin (Fig. 7b,c), PDE6 (Fig. $7 e, f)$, RDS2 (Fig. 7h,i), or of other integral or peripheral membrane proteins (supplemental Fig. S7, available at www.jneurosci. org as supplemental material), although numerous pyknotic nuclei indicate an advanced stage of degeneration (arrows in Fig. $7 b, e, h$; supplemental Fig. S6, available at www.jneurosci.org as supplemental material). However, some ONL accumulation of rhodopsin was observed in P14/P21 ${ }^{r} \mathrm{Kif}_{3} a^{-1-}$ rods when semithin sections were probed with 1D4 $\mathrm{mAb}$ and visualized with silver-intensified gold particles (supplemental Fig. S8c,f, available at www.jneurosci.org as supplemental material). Importantly, the bulk of rhodopsin is present in the outer segments. At P28 (Fig. 8), although rod degeneration is far advanced, the ONL is reduced to three or four layers of nuclei, and some membrane proteins, particularly PDE6 (Fig. $8 d$ ) and transducin $\alpha$-subunit and cone terminals in the absence of KIF3A. Therefore, these data are interpreted to suggest that heterotrimeric kinesin-II is not involved in long-distance trafficking along microtubules toward the plus end near the photoreceptor synaptic terminals.

\section{Discussion}

The effect of KIF3A deletion on transport of phototransduction proteins was studied in cone and rod photoreceptors. Our results indicate that, in cones, the heterotrimeric kinesin-II motor is essential for anterograde transport of a subset of membrane proteins involved in phototransduction, whereas, in rods, kinesin-II is not required. This differential result was unexpected since rods and cones share similar morphologies, renew their outer segments every $10 \mathrm{~d}$, use identical or highly homologous polypeptides to execute phototransduction, and require anterograde IFT along plus-ended microtubules. 


\section{Mutant cones show mistargeting of membrane proteins}

In the current model of post-Golgi transport of integral membrane proteins (LippincottSchwartz et al., 2000; Rodriguez-Boulan et al., 2005), vesicles emerging from the TGN traffic along microtubules powered by retrograde motors. After fusion of vesicles bearing transmembrane proteins with the plasma membrane, cargo is assembled and transported through the cilium by an anterograde molecular motor. Our results indicate that the anterograde molecular motor primarily responsible for IFT in cone photoreceptors is heterotrimeric kinesin-II. Deletion of the subunit KIF3A motor results in the following defects: Misorganization of the outer segment membrane at P13 (Fig. 4), mislocalization of visual pigments (Fig. 1; supplemental Fig. S1, available at www.jneurosci. org as supplemental material), and absence of membrane-associated polypeptides of the cone phototransduction cascade (Fig. 2 ), as well as integral outer segment membrane proteins (Fig. 3). In ${ }^{c} \mathrm{Kif} 3 \mathrm{a}^{-1-}$ cones, $\mathrm{S}$ - and M/L-opsins appear trapped in membranes of the inner and outer segment, the outer nuclear layer, and synaptic terminals (Fig. 1; supplemental Figs. S1, S2, available at www.jneurosci.org as supplemental material). The small amount of the visual pigments observed in the outer segments (Fig. $1 C b)$ was likely transported there before sufficient Cre expression deleted kinesin-II. Alternatively, opsins may have been transported by redundant, but less efficient anterograde alternate motor polypeptides [e.g., myosin-VIIa (Williams, 2002) or KIF17 (Jenkins et al., 2006; Insinna et al., 2008)], or the opsins may simply distribute throughout the cell membrane, the final destination of the secretory pathway, by lateral diffusion when IFT is defunct. Most remarkably, essentially all key polypeptides of the cone phototransduction cascade fail to traffic properly in the absence of kinesin-II, consistent with nonrecordable ERG responses at P14 (supplemental Fig. S3, available at www.jneurosci.org as supplemental material) and P30 (Fig. $1 B$ ). These proteins are critically important not only for phototransduction but also contribute to outer segment structural stability and photoreceptor survival. In human patients, null alleles and missense mutations in genes encoding outer segment proteins lead to a variety of retinal dystrophies, including retinitis pigmentosa, Leber congenital amaurosis, cone dystrophies, and macular degeneration.

Cone pigment mistargeting was observed previously in mutant cones lacking guanylate cyclase-1 (GC1) (Baehr et al., 2007), retinoid isomerohydrolase (RPE65) (Rohrer et al., 2005; Znoiko et al., 2005), bar, $10 \mu \mathrm{m}$.

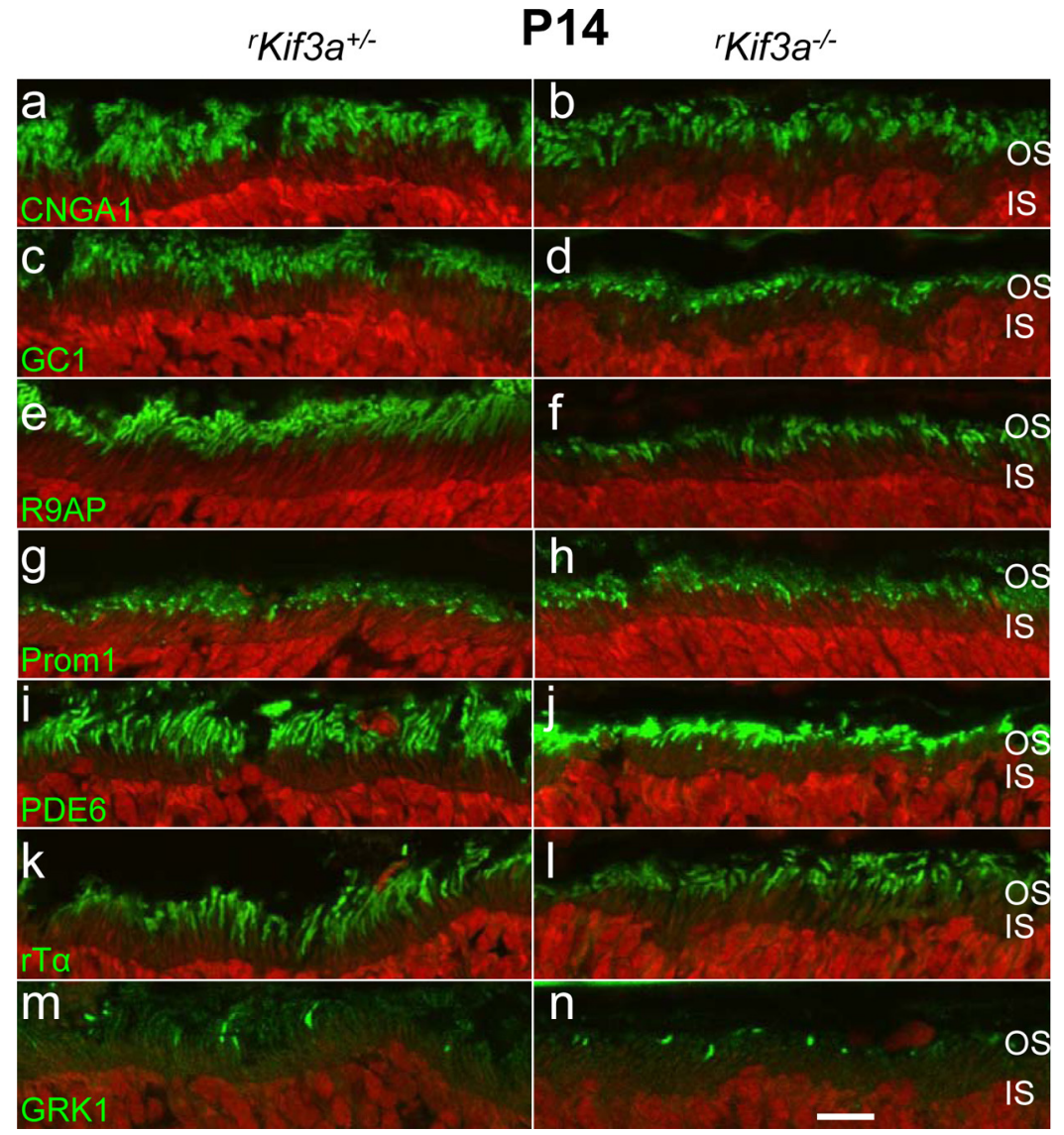

Figure 6. Confocal localization of phototransduction proteins. Sections of ${ }^{r} K i f 3 a^{+/-}(\boldsymbol{a}, \boldsymbol{c}, \boldsymbol{e}, \boldsymbol{g}, \boldsymbol{i}, \boldsymbol{k}, \boldsymbol{m})$ and ${ }^{r} K i f 3 a^{-1-}(\boldsymbol{b}, \boldsymbol{d}, \boldsymbol{f}$, $\boldsymbol{h}, \boldsymbol{j}, \boldsymbol{l}, \boldsymbol{n})$ retina were probed with anti-CNGA1 $(\boldsymbol{a}, \boldsymbol{b})$, anti-GC1 $(\boldsymbol{c}, \boldsymbol{d})$, anti-R9AP $(\boldsymbol{e}, \boldsymbol{f})$, anti-prom1 $(\boldsymbol{g}, \boldsymbol{h})$, anti-rod PDE6 $(\boldsymbol{i}, \boldsymbol{j})$, anti-rod $\operatorname{T} \alpha(\boldsymbol{k}, \boldsymbol{I})$, and anti-GRK1 $(\boldsymbol{m}, \boldsymbol{n})$ antibodies. All panels show normal transport and localization of membrane proteins to the outer segments. Scale bar, $10 \mu \mathrm{m}$.

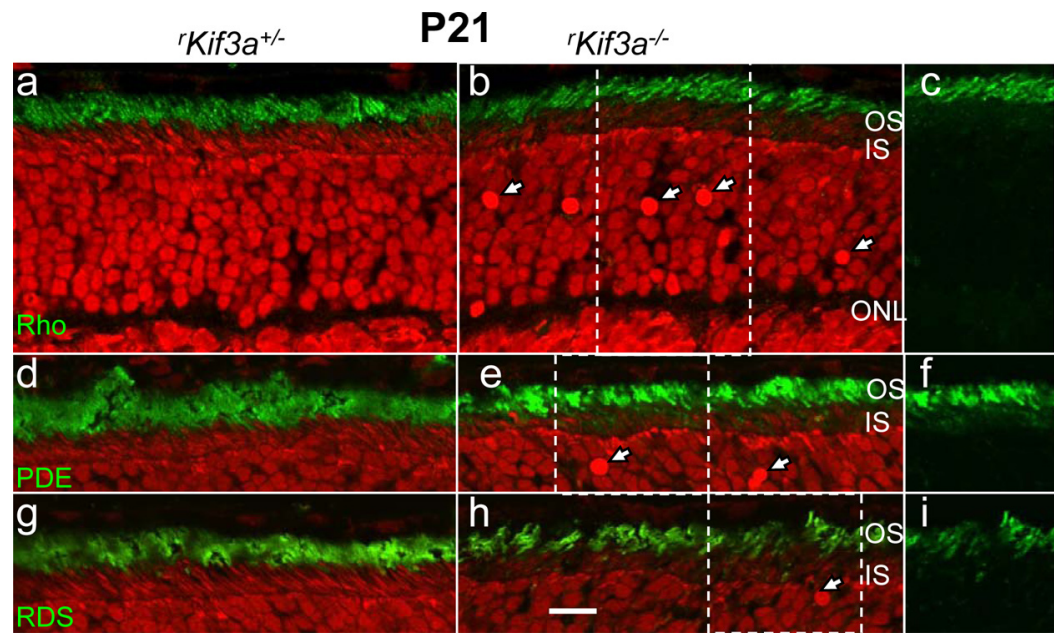

Figure 7. Trafficking of rhodopsin, PDE6 subunits, and peripherin/rds in P21 ${ }^{r} K i f 3 a^{-/-}$rods. Left column $(\boldsymbol{a}, \boldsymbol{d}, \boldsymbol{g}),{ }^{r} \mathrm{Kif3} \mathrm{a}^{+/-}$ retina sections; middle column $(\boldsymbol{b}, \boldsymbol{e}, \boldsymbol{h}),{ }^{r} K i f 3 a^{-1-}$ retina sections; and right column $(\boldsymbol{c}, \boldsymbol{f}, \boldsymbol{i})$, portions of corresponding sections $(\boldsymbol{b}, \boldsymbol{e}, \boldsymbol{h})$, green channel only. Sections $\boldsymbol{a}-\boldsymbol{c}$, Anti-rhodopsin; sections $\boldsymbol{d}-\boldsymbol{f}$, anti-PDE6 antibody; sections $\boldsymbol{g}-\boldsymbol{i}$, anti-peripherin/rds antibody. Note that rhodopsin traffics normally and does not mislocalize at P21. The white arrows indicate pyknotic nuclei. Scale

lecithin:retinol acyl transferase (LRAT) (Zhang et al., 2008), the cone CNG channel $\alpha$-subunit (CNGA3) (Michalakis et al., 2005), BBS4 (Abd-El-Barr et al., 2007), and complement factor H (Coffey et al., 2007), suggesting that vesicular and intraflagellar transport in cones 


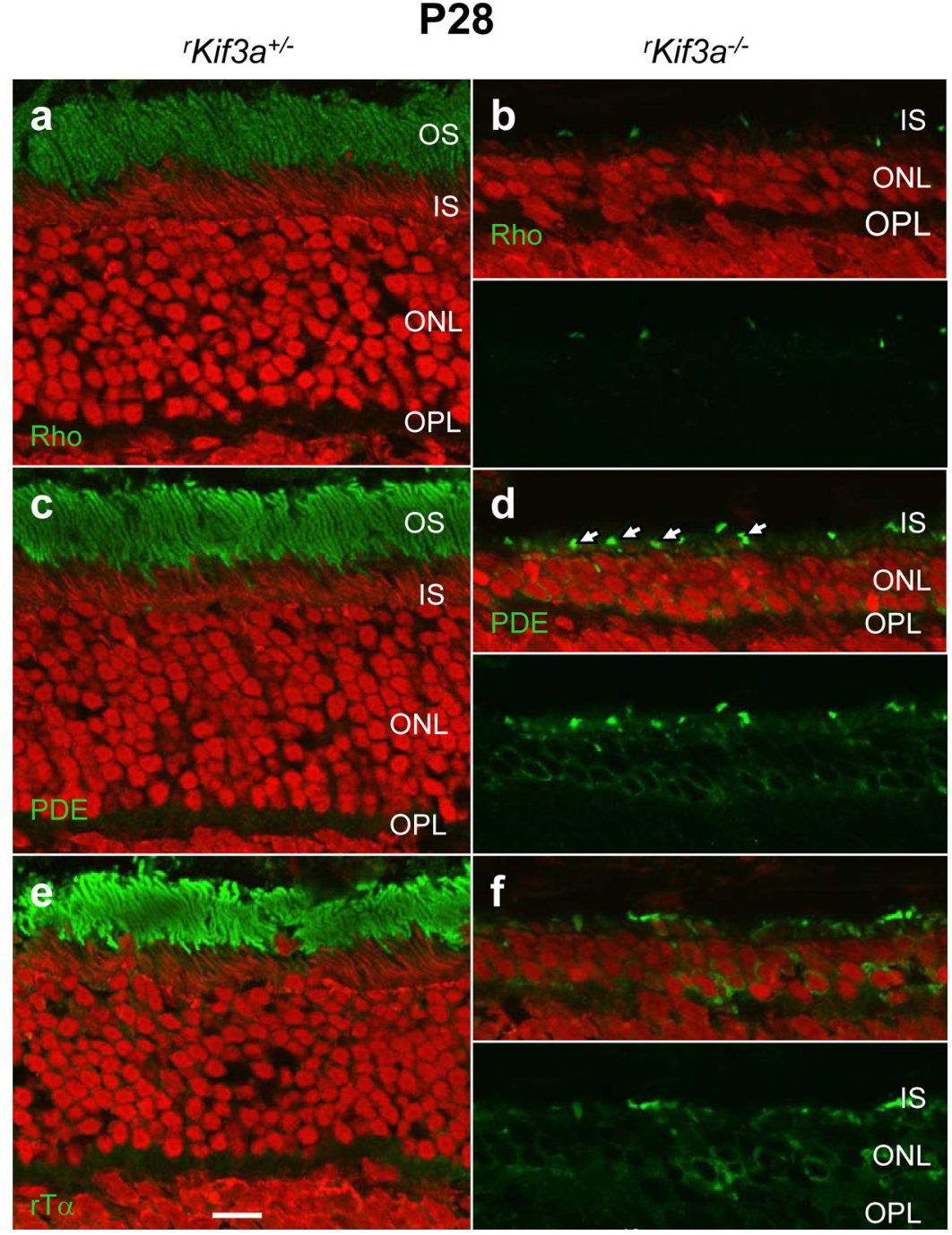

Figure 8. Rapid degeneration of ${ }^{r} K i f 3 a^{-1-}$ rod photoreceptors at P28. Sections of ${ }^{r} K_{i f 3} a^{+/-}(\boldsymbol{a}, \boldsymbol{c}, \boldsymbol{e})$ and ${ }^{r} K i f 3 a^{-1-}(\boldsymbol{b}, \boldsymbol{d}, \boldsymbol{f})$ retina were probed with anti-rhodopsin $(\boldsymbol{a}, \boldsymbol{b})$, anti-rod PDE6 $(\boldsymbol{c}, \boldsymbol{d})$, and anti-transducin $\alpha$-subunit antibodies $(\boldsymbol{e}, \boldsymbol{f})$. Rod outer segments in ${ }^{r} K i f 3 a^{-1-}$ sections were absent and the ONL is reduced to three to four rows. The bottom panels in $\boldsymbol{b}, \boldsymbol{d}$, and $\boldsymbol{f}$ show green channel only. In $\boldsymbol{b}$, very little rhodopsin remains in the outer segments. In $\boldsymbol{d}$, punctuate green fluorescence (arrows) indicates remnants of cone outer segments (labeled with MOE, an antibody that recognizes both rod and cone PDE6). Scale bar, $10 \mu \mathrm{m}$.

is dependent on a number of gene products/cofactors. In particular, the ${ }^{c} \mathrm{Kif}_{3} \mathrm{a}^{-1-}$ phenotype is strikingly similar to that observed in GC1 (Baehr et al., 2007), LRAT, and RPE65 knock-out mice (Fan et al., 2008; Zhang et al., 2008) producing rapid cone degeneration phenotypes. In mutant cones, lacking GC1 or the chromophore 11-cis-retinal, respectively, visual pigments are mistargeted and phototransduction polypeptides are absent in outer segments. Phenotypic similarity among several genetically altered mice, in which knocking out one gene disrupts the function of seemingly unconnected gene products, suggests assembly of a large cargo that depends on multiple factors (11-cis-retinal, GC1, molecular motors) for vesicle formation, inner segment transport and anterograde intraflagellar transport.

\section{Mutant rods degenerate rapidly, but membrane proteins traffic to the outer segments}

In rods, however, heterotrimeric kinesin-II is not required for transport of membrane proteins (Figs. 5-7; supplemental Figs. S5, S7, S8, available at www.jneurosci.org as supplemental material). Using a different Cre driver [iCre75 (Li et al., 2008)] than used previously
[Rho-Cre-8 (Jimeno et al., 2006)], we found that at P14 KIF3A is essentially absent in ${ }^{r} \mathrm{Kif3}^{-1-}$ rods (Fig. 5D). Nevertheless, rhodopsin and other phototransduction proteins apparently traffic to the ${ }^{r} \mathrm{Kif} 3 \mathrm{a}^{-1-}$ rod outer segments at P14 and P21 (Fig. 6; supplemental Fig. S6, available at www.jneurosci.org as supplemental material) virtually unimpeded. Furthermore, none of the proteins residing in the outer segment is degraded in P14 ${ }^{r} \mathrm{Kif3a}^{-1-}$ rods (Fig. $5 \mathrm{C}$ ), in contrast to the degradation observed in ${ }^{c} \mathrm{Kif} 3 \mathrm{a}^{-1-}$ cones (Fig. $2 B$ ). This result is in apparent conflict with previously reported early rhodopsin accumulation in the ONL of Kif $3 a^{\text {flox } / f l o x}$ Rho-Cre- $8^{+}$mice originating

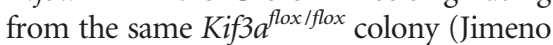
et al., 2006). To obtain evidence of rhodopsin trafficking independent from confocal microscopy, we analyzed P14 silverstained semithin sections as published in the study by Jimeno et al. (2006), relative to P14 and P21 semithin sections of this study (supplemental Fig. S8, available at www.jneurosci.org as supplemental material). The results show that, in both mutant lines, the bulk of rhodopsin trafficked to the outer segments but accumulated to some degree in the ONL. Apparently, rod degeneration proceeded faster in the study of Jimeno et al., reporting opsin mislocalization at P7 and severe rod degeneration at P14, a time when outer segments are still developing. The accumulation likely occurs in membranes in which rhodopsin transiently resides when trafficking from the ER to the outer segments. Our interpretation of this phenotype is that most likely outer segment degeneration precedes rhodopsin accumulation, and that the accumulation is a consequence of degeneration. Early degeneration events could impede transport to the outer segment, resulting in a "traffic jam" of nascent opsin unable to traffic normally since its final destination, the outer segment, is degenerating. In this study, severe, rapid degeneration of ${ }^{r} \mathrm{Kif}_{3} \mathrm{a}^{-1-}$ rod photoreceptors occurs between P14 and P28. At P28, one observes only three to four rows of nuclei in the ONL and outer segment remnants (Fig. 8). The event that triggers this rapid cell death is unknown and must precede P14 since scotopic ERG a-waves, an indicator of rod function, are severely diminished (Fig. 5A). We emphasize that the earliest documented cell biological event is absence of KIF3A in rod cells (Fig. 5D), consistent with appearance of the diagnostic deletion fragment (Fig. 5B) signaling activity of Cre recombinase. Based on the relatively normal trafficking pattern in rods lacking heterotrimeric kinesin-II, we consider it unlikely that kinesin-II is required for anterograde IFT of rod membrane proteins. We note that homodimeric kinesin-II (KIF17) immunolocalized to inner segment vesicles and connecting cilia microtubules of WT mouse rods (Insinna et al., 2009). Thus, rods may use KIF17 as an alternate motor for membrane protein transport. It was shown recently that the ol- 
A P28

\section{cone Kif3a deletion}

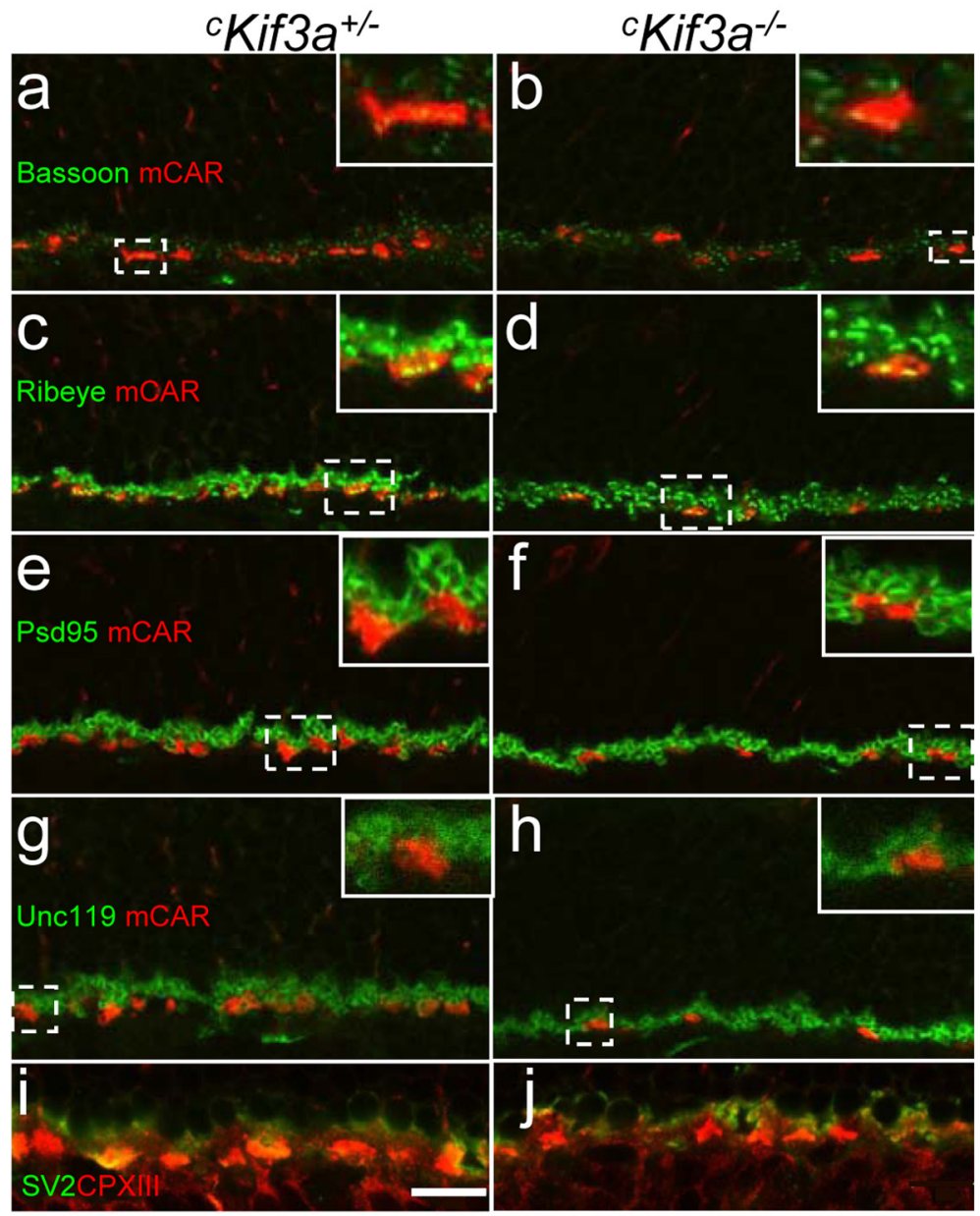

B P14

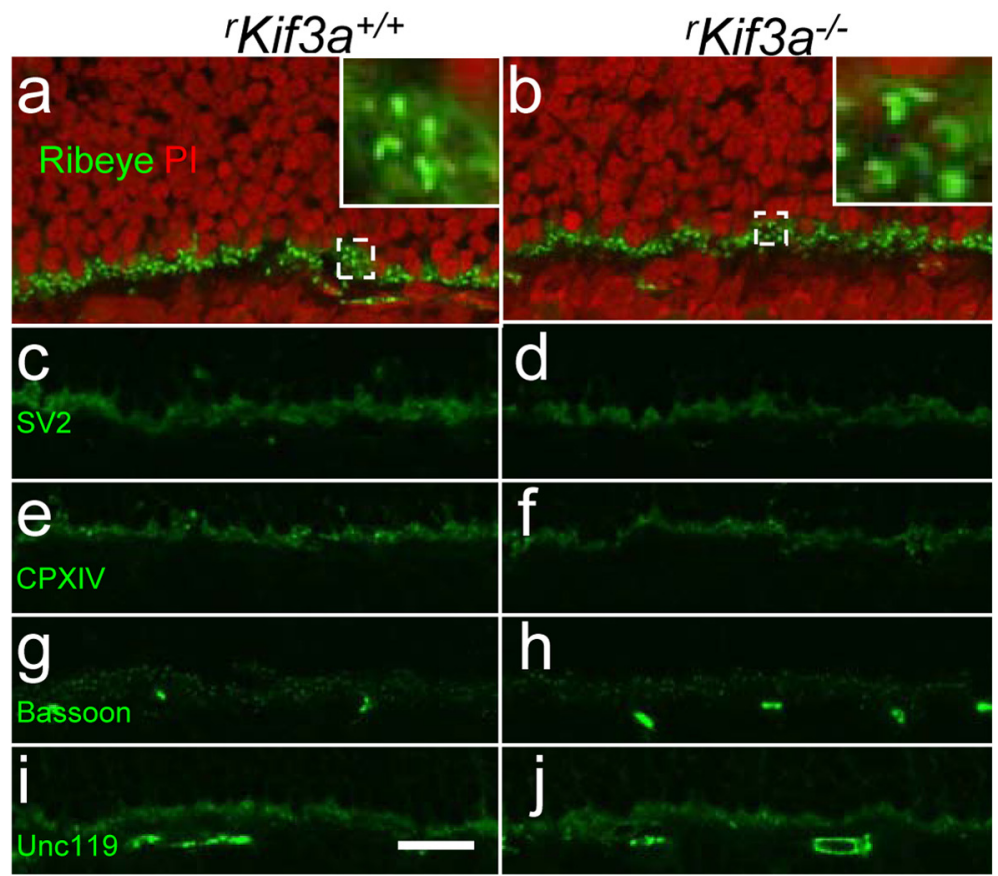

Figure 9. Synaptic terminal membrane proteins appear unaffected by KIF3A deletion. $A$, KIF3A deletion in cones. 'Kif3a ${ }^{+/}$ $(\boldsymbol{a}, \boldsymbol{c}, \boldsymbol{e}, \boldsymbol{g}, \boldsymbol{i})$ and ${ }^{C} \mathrm{Kif3} a^{-1-}(\boldsymbol{b}, \boldsymbol{d}, \boldsymbol{f}, \boldsymbol{h}, \boldsymbol{j})$ sections were probed with anti-bassoon (green) and anti-mCAR (red) antibodies $(\boldsymbol{a}, \boldsymbol{b})$, anti-ribeye factory channel $\alpha$-subunit (CNGA2), a close relative of the rod channel CNGA1, required KIF17 for correct targeting in olfactory neurons (Jenkins et al., 2006), and in zebrafish, KIF17 was shown to be associated with the ciliary axoneme of rods as well as single and double cones (Insinna et al., 2008). A knockdown of KIF17 with antisense morpholinos affected trafficking of cone pigments strongly, and trafficking of rhodopsin and CNGA1 moderately. Consequently, homodimeric kinesin-II consisting of two KIF17 subunits may be a viable candidate for rod IFT in mouse.

A rapid rod degeneration phenotype was also observed in Xenopus laevis when a dominant-negative kinesin-II transgene was expressed (Lin-Jones et al., 2003). Based on the observed rapid degeneration in kinesin-II-deficient rods in two different mouse models, kinesin-II must serve an important role in rod structure. From these results, it is obvious that kinesin-II is vital for survival of rods, but its precise function in anterograde transport remains to be elucidated.

Different motors for rods and cones Why might the relative importance of different molecular motors differ between rods and cones, even though rods and cones have similar polarized structures, function, and molecular composition? Evolutionarily, cones developed first and rods developed later, as determined by the branching pattern of vertebrate opsins (Lamb et al., 2007). After diverging, rods developed an OS consisting of a coin-like stack of discs ( $\sim 800$ discs/ROS in mouse), probably to increase photon capture and sensitivity. Mouse COSs, in contrast, have a zigzag layering of discs, although some independent discs similar to rod discs were observed (Anderson et al., 1978). Thus, a significant difference exists in OS shape and dimension: mouse ROSs are two to three times longer than COSs and have a three to four times larger volume [36 and 10 al $\left.\left(10^{-18} \mathrm{~L}\right)\right]$, respectively, as calculated from data of Carter-Dawson

$\leftarrow$

(green) and anti mCAR $(\boldsymbol{c}, \boldsymbol{d})$, anti-PSD95 (green) and antimCAR (e, f), anti-Unc119 (green) and anti-mCAR antibodies $(\boldsymbol{g}, \boldsymbol{h})$, and with anti-SV2 (green) and anti-CPX-III (red) antibodies. The insets show enlargements identified by broken lines. $\boldsymbol{B}, \mathrm{KIF} 3 \mathrm{~A}$ deletion in rods. ${ }^{r} \mathrm{Kif3} a^{+/-}(\boldsymbol{a}, \boldsymbol{c}, \boldsymbol{e}, \boldsymbol{g}, \boldsymbol{i})$ and ${ }^{r} K i f 3 a^{-1-}(\boldsymbol{b}, \boldsymbol{d}, \boldsymbol{f}, \boldsymbol{h}, \boldsymbol{j})$ sections were probed with ribeye antibody $(\boldsymbol{a}, \boldsymbol{b})$, anti-SV2 antibody $(\boldsymbol{c}, \boldsymbol{d})$, anti-CPX-IV $(\boldsymbol{e}, \boldsymbol{f})$, antibassoon $(\boldsymbol{g}, \boldsymbol{h})$, and anti-Unc119 antibodies $(\boldsymbol{i}, \boldsymbol{j})$. Nuclei of the ONL and INL were counterstained with propidium iodide to clearly mark the OPL region $(\boldsymbol{a}, \boldsymbol{b})$. The insets $(\boldsymbol{a}, \boldsymbol{b})$ show enlarged regions identified by broken lines. Scale bar, $10 \mu \mathrm{m}$. 
and LaVail (1979) and Nickell et al. (2007). Yet both rod and cone outer segments are replaced every $10 \mathrm{~d}$, requiring a three to four times more active IFT machinery for rods. Interestingly, at least in C. elegans, heterotrimeric kinesin-II and OSM-3 (KIF17) have been shown to travel along the axoneme at speeds that differ approximately threefold: kinesin-II travels at $0.5 \mu \mathrm{m} / \mathrm{s}$, and OSM-3 at $1.3 \mu \mathrm{m} / \mathrm{s}$ (Scholey, 2008). The relatively slow speed of kinesin-II could suffice for the shorter cone axoneme, whereas rods may require the faster OSM-3. Resolution of this question may follow analysis of rod-specific, targeted deletion of OSM-3.

\section{References}

Abd-El-Barr MM, Sykoudis K, Andrabi S, Eichers ER, Pennesi ME, Tan PL, Wilson JH, Katsanis N, Lupski JR, Wu SM (2007) Impaired photoreceptor protein transport and synaptic transmission in a mouse model of Bardet-Biedl syndrome. Vision Res 47:3394-3407.

Anderson DH, Fisher SK, Steinberg RH (1978) Mammalian cones: disc shedding, phagocytosis, and renewal. Invest Ophthalmol Vis Sci 17:117-133.

Applebury ML, Antoch MP, Baxter LC, Chun LL, Falk JD, Farhangfar F, Kage K, Krzystolik MG, Lyass LA, Robbins JT (2000) The murine cone photoreceptor: a single cone type expresses both $\mathrm{S}$ and $\mathrm{M}$ opsins with retinal spatial patterning. Neuron 27:513-523.

Baehr W, Karan S, Maeda T, Luo DG, Li S, Bronson JD, Watt CB, Yau KW, Frederick JM, Palczewski K (2007) The function of guanylate cyclase 1 and guanylate cyclase 2 in rod and cone photoreceptors. J Biol Chem 282:8837-8847.

Baker SA, Freeman K, Luby-Phelps K, Pazour GJ, Besharse JC (2003) IFT20 links kinesin II with a mammalian intraflagellar transport complex that is conserved in motile flagella and sensory cilia. J Biol Chem 278:34211-34218.

Besharse JC, Hollyfield JG (1979) Turnover of mouse photoreceptor outer segments in constant light and darkness. Invest Ophthalmol Vis Sci 18:1019-1024.

Brown JM, Marsala C, Kosoy R, Gaertig J (1999) Kinesin-II is preferentially targeted to assembling cilia and is required for ciliogenesis and normal cytokinesis in Tetrahymena. Mol Biol Cell 10:3081-3096.

Carter-Dawson LD, LaVail MM (1979) Rods and cones in the mouse retina. I. Structural analysis using light and electron microscopy. J Comp Neurol 188:245-262.

Choy E, Chiu VK, Silletti J, Feoktistov M, Morimoto T, Michaelson D, Ivanov IE, Philips MR (1999) Endomembrane trafficking of ras: the CAAX motif targets proteins to the ER and Golgi. Cell 98:69-80.

Coffey PJ, Gias C, McDermott CJ, Lundh P, Pickering MC, Sethi C, Bird A, Fitzke FW, Maass A, Chen LL, Holder GE, Luthert PJ, Salt TE, Moss SE, Greenwood J (2007) Complement factor H deficiency in aged mice causes retinal abnormalities and visual dysfunction. Proc Natl Acad Sci U S A 104:16651-16656.

Cole DG, Cande WZ, Baskin RJ, Skoufias DA, Hogan CJ, Scholey JM (1992) Isolation of a sea urchin egg kinesin-related protein using peptide antibodies. J Cell Sci 101:291-301.

Cole DG, Diener DR, Himelblau AL, Beech PL, Fuster JC, Rosenbaum JL (1998) Chlamydomonas kinesin-II-dependent intraflagellar transport (IFT): IFT particles contain proteins required for ciliary assembly in Caenorhabditis elegans sensory neurons. J Cell Biol 141:993-1008.

Deretic D (1998) Post-Golgi trafficking of rhodopsin in retinal photoreceptors. Eye 12:526-530.

Fan J, Rohrer B, Frederick JM, Baehr W, Crouch RK (2008) Rpe65 ${ }^{-1-}$ and Lrat $^{-1-}$ mice: comparable models of Leber Congenital Amaurosis. Invest Ophthalmol Vis Sci 49:2384-2389.

Green ES, Menz MD, LaVail MM, Flannery JG (2000) Characterization of rhodopsin mis-sorting and constitutive activation in a transgenic rat model of retinitis pigmentosa. Invest Ophthalmol Vis Sci 41:1546-1553.

Haeseleer F (2008) Interaction and colocalization of CaBP4 and Unc119 (MRG4) in photoreceptors. Invest Ophthalmol Vis Sci 49:2366-2375.

Haverkamp S, Wässle H, Duebel J, Kuner T, Augustine GJ, Feng G, Euler T (2005) The primordial, blue-cone color system of the mouse retina. J Neurosci 25:5438-5445.

Heidelberger R, Thoreson WB, Witkovsky P (2005) Synaptic transmission at retinal ribbon synapses. Prog Retin Eye Res 24:682-720.

Hu G, Wensel TG (2002) R9AP, a membrane anchor for the photoreceptor
GTPase accelerating protein, RGS9-1. Proc Natl Acad Sci U S A 99:9755-9760.

Insinna C, Pathak N, Perkins B, Drummond I, Besharse JC (2008) The homodimeric kinesin, Kif17, is essential for vertebrate photoreceptor sensory outer segment development. Dev Biol 316:160-170.

Insinna C, Humby M, Sedmak T, Wolfrum U, Besharse JC (2009) Different roles for KIF17 and kinesin II in photoreceptor development and maintenance. Dev Dyn 238:2211-2222.

Jászai J, Fargeas CA, Florek M, Huttner WB, Corbeil D (2007) Focus on molecules: prominin-1 (CD133). Exp Eye Res 85:585-586.

Jenkins PM, Hurd TW, Zhang L, McEwen DP, Brown RL, Margolis B, Verhey KJ, Martens JR (2006) Ciliary targeting of olfactory CNG channels requires the CNGB1b subunit and the kinesin-2 motor protein, KIF17. Curr Biol 16:1211-1216.

Jimeno D, Feiner L, Lillo C, Teofilo K, Goldstein LS, Pierce EA, Williams DS (2006) Analysis of kinesin-2 function in photoreceptor cells using synchronous Cre-loxP knockout of Kif3a with RHO-Cre. Invest Ophthalmol Vis Sci 47:5039-5046.

Jones BW, Watt CB, Frederick JM, Baehr W, Chen CK, Levine EM, Milam AH, Lavail MM, Marc RE (2003) Retinal remodeling triggered by photoreceptor degenerations. J Comp Neurol 464:1-16.

Karan S, Zhang H, Li S, Frederick JM, Baehr W (2008) A model for transport of membrane-associated phototransduction polypeptides in rod and cone photoreceptor inner segments. Vision Res 48:442-452.

Kaupp UB, Seifert R (2002) Cyclic nucleotide-gated ion channels. Physiol Rev 82:769-824.

Kleinman ME, Ambati J (2008) Fifty years later: the disk goes to the prom. J Clin Invest 118:2681-2684.

Kobayashi A, Kubota S, Mori N, McLaren MJ, Inana G (2003) Photoreceptor synaptic protein HRG4 (UNC119) interacts with ARL2 via a putative conserved domain. FEBS Lett 534:26-32.

Lamb TD, Collin SP, Pugh EN Jr (2007) Evolution of the vertebrate eye: opsins, photoreceptors, retina and eye cup. Nat Rev Neurosci 8:960-976.

LaVail MM (1976) Rod outer segment disk shedding in rat retina: relationship to cyclic lighting. Science 194:1071-1074.

Le Y, Gagneten S, Tombaccini D, Bethke B, Sauer B (1999) Nuclear targeting determinants of the phage P1 cre DNA recombinase. Nucleic Acids Res 27:4703-4709.

Le YZ, Ash JD, Al-Ubaidi MR, Chen Y, Ma JX, Anderson RE (2004) Targeted expression of Cre recombinase to cone photoreceptors in transgenic mice. Mol Vis 10:1011-1018.

Le YZ, Zheng L, Zheng W, Ash JD, Agbaga MP, Zhu M, Anderson RE (2006) Mouse opsin promoter-directed Cre recombinase expression in transgenic mice. Mol Vis 12:389-398.

Le Bot N, Antony C, White J, Karsenti E, Vernos I (1998) Role of xklp3, a subunit of the Xenopus kinesin II heterotrimeric complex, in membrane transport between the endoplasmic reticulum and the Golgi apparatus. J Cell Biol 143:1559-1573.

Lee ES, Burnside B, Flannery JG (2006) Characterization of peripherin/rds and rom-1 transport in rod photoreceptors of transgenic and knockout animals. Invest Ophthalmol Vis Sci 47:2150-2160.

Li S, Chen D, Sauvé Y, McCandless J, Chen YJ, Chen CK (2008) RhodopsiiCre transgenic mouse line for Cre-mediated rod-specific gene targeting. Genesis 41:73-80.

Lin F, Hiesberger T, Cordes K, Sinclair AM, Goldstein LS, Somlo S, Igarashi P (2003) Kidney-specific inactivation of the KIF3A subunit of kinesin-II inhibits renal ciliogenesis and produces polycystic kidney disease. Proc Natl Acad Sci U S A 100:5286-5291.

Lin-Jones J, Parker E, Wu M, Knox BE, Burnside B (2003) Disruption of kinesin II function using a dominant negative-acting transgene in Xenopus laevis rods results in photoreceptor degeneration. Invest Ophthalmol Vis Sci 44:3614-3621.

Lippincott-Schwartz J, Roberts TH, Hirschberg K (2000) Secretory protein trafficking and organelle dynamics in living cells. Annu Rev Cell Dev Biol 16:557-589.

Marszalek JR, Ruiz-Lozano P, Roberts E, Chien KR, Goldstein LS (1999) Situs inversus and embryonic ciliary morphogenesis defects in mouse mutants lacking the KIF3A subunit of kinesin-II. Proc Natl Acad Sci U S A 96:5043-5048.

Marszalek JR, Liu X, Roberts EA, Chui D, Marth JD, Williams DS, Goldstein LS (2000) Genetic evidence for selective transport of opsin and arrestin by kinesin-II in mammalian photoreceptors. Cell 102:175-187. 
Michaelson D, Ahearn I, Bergo M, Young S, Philips M (2002) Membrane trafficking of heterotrimeric $\mathrm{G}$ proteins via the endoplasmic reticulum and Golgi. Mol Biol Cell 13:3294-3302.

Michalakis S, Geiger H, Haverkamp S, Hofmann F, Gerstner A, Biel M (2005) Impaired opsin targeting and cone photoreceptor migration in the retina of mice lacking the cyclic nucleotide-gated channel CNGA3. Invest Ophthalmol Vis Sci 46:1516-1524.

Morris RL, Scholey JM (1997) Heterotrimeric kinesin-II is required for the assembly of motile $9+2$ ciliary axonemes on sea urchin embryos. J Cell Biol 138:1009-1022.

Muresan V, Lyass A, Schnapp BJ (1999) The kinesin motor KIF3A is a component of the presynaptic ribbon in vertebrate photoreceptors. J Neurosci 19:1027-1037.

Nickell S, Park PS, Baumeister W, Palczewski K (2007) Three-dimensional architecture of murine rod outer segments determined by cryoelectron tomography. J Cell Biol 177:917-925.

Nishimura DY, Fath M, Mullins RF, Searby C, Andrews M, Davis R, Andorf JL, Mykytyn K, Swiderski RE, Yang B, Carmi R, Stone EM, Sheffield VC (2004) Bbs2-null mice have neurosensory deficits, a defect in social dominance, and retinopathy associated with mislocalization of rhodopsin. Proc Natl Acad Sci U S A 101:16588-16593.

Pazour GJ, Baker SA, Deane JA, Cole DG, Dickert BL, Rosenbaum JL, Witman GB, Besharse JC (2002) The intraflagellar transport protein, IFT88, is essential for vertebrate photoreceptor assembly and maintenance. J Cell Biol 157:103-113.

Reim K, Wegmeyer H, Brandstätter JH, Xue M, Rosenmund C, Dresbach T, Hofmann K, Brose N (2005) Structurally and functionally unique complexins at retinal ribbon synapses. J Cell Biol 169:669-680.

Rodriguez-Boulan E, Kreitzer G, Müsch A (2005) Organization of vesicular trafficking in epithelia. Nat Rev Mol Cell Biol 6:233-247.

Rohrer B, Lohr HR, Humphries P, Redmond TM, Seeliger MW, Crouch RK (2005) Cone opsin mislocalization in Rpe65 ${ }^{-1-}$ mice: a defect that can be corrected by 11-cis retinal. Invest Ophthalmol Vis Sci 46:3876-3882.

Rosenbaum JL, Witman GB (2002) Intraflagellar transport. Nat Rev Mol Cell Biol 3:813-825.

Sanmartí-Vila L, tom Dieck S, Richter K, Altrock W, Zhang L, Volknandt W, Zimmermann H, Garner CC, Gundelfinger ED, Dresbach T (2000) Membrane association of presynaptic cytomatrix protein bassoon. Biochem Biophys Res Commun 275:43-46.

Schmitz F, Königstorfer A, Südhof TC (2000) RIBEYE, a component of synaptic ribbons: a protein's journey through evolution provides insight into synaptic ribbon function. Neuron 28:857-872.

Scholey JM (2008) Intraflagellar transport motors in cilia: moving along the cell's antenna. J Cell Biol 180:23-29.

Snow JJ, Ou G, Gunnarson AL, Walker MR, Zhou HM, Brust-Mascher I, Scholey JM (2004) Two anterograde intraflagellar transport motors cooperate to build sensory cilia on C. elegans neurons. Nat Cell Biol 6:1109-1113.

Strauss O (2005) The retinal pigment epithelium in visual function. Physiol Rev 85:845-881.

Sung CH, Tai AW (2000) Rhodopsin trafficking and its role in retinal dystrophies. Int Rev Cytol 195:215-267.

Tabish M, Siddiqui ZK, Nishikawa K, Siddiqui SS (1995) Exclusive expres- sion of C. elegans osm-3 kinesin gene in chemosensory neurons open to the external environment. J Mol Biol 247:377-389.

tom Dieck S, Sanmartí-Vila L, Langnaese K, Richter K, Kindler S, Soyke A, Wex H, Smalla KH, Kämpf U, Fränzer JT, Stumm M, Garner CC, Gundelfinger ED (1998) Bassoon, a novel zinc-finger CAG/glutaminerepeat protein selectively localized at the active zone of presynaptic nerve terminals. J Cell Biol 142:499-509.

tom Dieck S, Altrock WD, Kessels MM, Qualmann B, Regus H, Brauner D, Fejtová A, Bracko O, Gundelfinger ED, Brandstätter JH (2005) Molecular dissection of the photoreceptor ribbon synapse: physical interaction of Bassoon and RIBEYE is essential for the assembly of the ribbon complex. J Cell Biol 168:825-836.

Tuma MC, Zill A, Le Bot N, Vernos I, Gelfand V (1998) Heterotrimeric kinesin II is the microtubule motor protein responsible for pigment dispersion in Xenopus melanophores. J Cell Biol 143:1547-1558.

Whitehead JL, Wang SY, Bost-Usinger L, Hoang E, Frazer KA, Burnside B (1999) Photoreceptor localization of the KIF3A and KIF3B subunits of the heterotrimeric microtubule motor kinesin II in vertebrate retina. Exp Eye Res 69:491-503.

Williams DS (2002) Transport to the photoreceptor outer segment by myosin VIIa and kinesin II. Vision Res 42:455-462.

Yamazaki H, Nakata T, Okada Y, Hirokawa N (1995) KIF3A/B: a heterodimeric kinesin superfamily protein that works as a microtubule plus end-directed motor for membrane organelle transport. J Cell Biol 130:1387-1399.

Yamazaki H, Nakata T, Okada Y, Hirokawa N (1996) Cloning and characterization of KAP3: a novel kinesin superfamily-associated protein of KIF3A/3B. Proc Natl Acad Sci U S A 93:8443-8448.

Yang J, Pawlyk B, Wen XH, Adamian M, Soloviev M, Michaud N, Zhao Y, Sandberg MA, Makino CL, Li T (2007) Mpp4 is required for proper localization of plasma membrane calcium ATPases and maintenance of calcium homeostasis at the rod photoreceptor synaptic terminals. Hum Mol Genet 16:1017-1029.

Yang Z, Chen Y, Lillo C, Chien J, Yu Z, Michaelides M, Klein M, Howes KA Li Y, Kaminoh Y, Chen H, Zhao C, Chen Y, Al-Sheikh YT, Karan G, Corbeil D, Escher P, Kamaya S, Li C, Johnson S, et al. (2008) Mutant prominin 1 found in patients with macular degeneration disrupts photoreceptor disk morphogenesis in mice. J Clin Invest 118:2908-2916.

Young RW (1967) The renewal of photoreceptor cell outer segments. J Cell Biol 33:61-72.

Young RW, Bok D (1969) Participation of the retinal pigment epithelium in the rod outer segment renewal process. J Cell Biol 42:392-403.

Zhang H, Li S, Doan T, Rieke F, Detwiler PB, Frederick JM, Baehr W (2007) Deletion of $\mathrm{PrBP} / \delta$ impedes transport of GRK1 and PDE6 catalytic subunits to photoreceptor outer segments. Proc Natl Acad Sci USA 104:8857-8862.

Zhang H, Fan J, Li S, Karan S, Rohrer B, Palczewski K, Frederick JM, Crouch RK, Baehr W (2008) Trafficking of membrane-associated proteins to cone photoreceptor outer segments requires the chromophore 11-cisretinal. J Neurosci 28:4008-4014.

Znoiko SL, Rohrer B, Lu K, Lohr HR, Crouch RK, Ma JX (2005) Downregulation of cone-specific gene expression and degeneration of cone photoreceptors in the Rpe $65^{-1-}$ mouse at early ages. Invest Ophthalmol Vis Sci 46:1473-1479. 